Revista lus et Praxis, Año 18, № 1, 2012, pp. 267 - 314

ISSN 0717 - 2877

Universidad de Talca - Facultad de Ciencias Jurídicas y Sociales

"Visión crítica desde el análisis económico del derecho al sistema de verificación de créditos y realización de activos de la ley de quiebras chilena"

Raúl Núñez Ojeda - Nicolás Carrasco Delgado - Francisco Ortiz Rojo

\title{
VISIÓN CRÍTICA DESDE EL ANÁLISIS ECONÓMICO DEL DERECHO AL SISTEMA DE VERIFICACIÓN DE CRÉDITOS Y REALIZACIÓN DE ACTIVOS DE LA LEY DE QUIEBRAS CHILENA*
}

\author{
A CRITICAL VIEW, FROM THE ECONOMIC ANALYSIS OF LAW, TO CLAIM'S \\ VERIFICATION AND ADMISSION SYSTEM, AND LIQUIDATION OF ASSETS, \\ IN CHILEAN BANKRUPTCY LAW
}

\author{
Raúl NúÑez OJedA* \\ Nicolás Carrasco Delgado ${ }^{* * *}$ \\ FRANCISCO ORTIZ ROJO ${ }^{* * * *}$
}

\begin{abstract}
RESUMEN
En el presente artículo, los autores sostienen que, desde la perspectiva del análisis económico del derecho, las etapas de verificación de créditos y realización de activos, en el marco de una quiebra, deben perseguir como objetivo normativo, una mayor recuperación de créditos. Para tal efecto, los autores describen dichas etapas, e indican sus deficiencias, proponiendo ciertas pautas de reforma enmarcadas en el análisis económico del derecho y el derecho comparado.

ABSTRACT

In this article, the authors adopt an approach based on the economic analysis of law to argue that the stages of verification and admission of claims, and of liquidation of assets, in bankruptcy cases, should aim to enhance recoveries and benefits for creditors, as a normative objective. In this regard, the authors describe these stages, pointing out the deficiencies of current law, and proposing certain guidelines for a reform framed in the economic analysis of law and in comparative law.
\end{abstract}

\footnotetext{
* Este trabajo se enmarca dentro del proyecto FONDECYT regular № 1100530, titulado "Hacia una nueva justicia concursal", cuyo investigador principal es el profesor Dr. Raúl Núñez Ojeda, de la Pontificia Universidad Católica de Valparaíso. Trabajo recibido el 4 de febrero y aprobado el 20 de abril de 2012.

** Licenciado en Ciencias Jurídicas por la Universidad de Valparaíso (Chile); Doctor en Derecho por la Universidad Pompeu Fabra de Barcelona (España); Profesor Asociado de Derecho Procesal en la Pontificia Universidad Católica de Valparaíso (Chile). Correo electrónico: raul.nunez@ucv.cl.

*** Licenciado en Ciencias Jurídicas y Sociales por la Universidad de Chile. Magíster con mención en Derecho Económico de la Facultad de Derecho de la Universidad de Chile. Ayudante de Derecho Procesal Universidad de Chile. Correo electrónico: ncarrascod@gmail.com.

**** Egresado de Derecho por la Universidad de Chile. Ayudante de Derecho Procesal Universidad de Chile. Correo electrónico: fjortizrojo@gmail.com.
} 
PALABRAS CLAVE

Derecho de Quiebras, Verificación de créditos, Liquidación de activos, Derecho, Análisis Económico del Derecho

KEYWORDS

Bankruptcy Law, Verification and Admission of Claims, Assets Liquidation, Economic Analysis of Law

\section{INTRODUCCIÓN}

El presente artículo tiene por objeto analizar dos etapas interdependientes del proceso de quiebras: la de verificación de créditos y la de realización de los activos. Ambos mecanismos procesales permiten saber qué acreedores serán pagados en un procedimiento de quiebra, qué monto recibirá cada uno y qué preferencias legales determinarán el orden de prioridad en que deben satisfacerse los créditos.

La hipótesis que se trabaja en esta oportunidad consiste en que dichas etapas tienen una regulación que las hace lentas e ineficientes. Esto produce que el procedimiento de quiebra demore excesivamente en la consecución de sus fines, generando mayores niveles de costos y dañando las expectativas de recuperación crediticia, tornándolas menos valiosas, en caso de existir.

Aumentar la celeridad del juicio de quiebra y reducir los costos de dicho procedimiento, constituyen ambos objetivos claves para lograr una mayor eficacia concursal ex post. Ello redundaría en mayores tasas de satisfacción de los acreedores y, por lo tanto, en un fortalecimiento de la confianza en el sistema de quiebras, lo que en términos generales permitiría el acceso al crédito en mejores condiciones.

Para abordar el presente tema, se comenzará exponiendo acerca de la eficiencia y el análisis económico del derecho. A partir de lo anterior, se determinará que el objetivo normativo a que debiera tender nuestra legislación de quiebras en relación con la verificación de créditos y la realización de activos, consiste en alcanzar una mayor eficacia concursal ex post (Acápite II). Luego, se describirá la normativa nacional sobre verificación de créditos y realización de activos, destacando la interdependencia que existe entre ambas etapas y su incidencia en la rapidez que puede revestir un proceso de quiebras. Esta descripción permitirá detectar las deficiencias e imperfecciones de que adolece el sistema concursal chileno, marcado fundamentalmente por su lentitud y por carecer de una asignación óptima de atribuciones legales (Acápite III). Posteriormente, se efectuará un estudio de distintos sistemas de verificación de créditos que ofrece el derecho comparado, constatando que aquellos que muestran una mayor tasa de reintegro de créditos son aquellos que han reducido los costos involucrados en un proceso de quiebra (Acápite IV). Por último, se concluirá el presente artículo señalando algunos linea- 
mientos generales para una reforma sobre la verificación de créditos y la realización del activo, conjugando una asimilación no agresiva de modelos comparados con la eficiencia concursal y el respeto a las garantías procesales (Acápite V).

\section{La Eficiencia y el Análisis Económico del Derecho}

Se ha afirmado anteriormente que la normativa sobre quiebras incluye directamente criterios de eficiencia ${ }^{1}$, lo cual significa que en las decisiones adoptadas a propósito de un procedimiento concursal se puede recurrir a la eficiencia como criterio normativo de adjudicación.

En este mismo sentido se ha pronunciado cierta jurisprudencia nacional. Así, la Excelentísima Corte Suprema ha tenido la oportunidad de ratificar las finalidades de eficiencia y de fortalecimiento de los órganos de la quiebra en un interesante y reciente fallo. En dicha ocasión declaró que:

"El legislador, al regular las materias concursales, lo hizo considerando por una parte, garantizar los derechos de los acreedores $y$, por otra parte, posibilitar que de la mejor forma se pague a los acreedores y que no se sacrifique, por circunstancias precisas y determinadas, la viabilidad del negocio del deudor. El derecho de quiebras tiene como principios: a) la par condictio creditorum, b) la protección adecuada del crédito, c) la conservación de la empresa, d) el aumento del poder de los órganos de la quiebra, e) la racionalidad económica: importa una preeminencia del factor económico en el contenido e interpretación de la norma de quiebra, manifestado especialmente en la preservación de la empresa para no desalentar la marcha económica" ${ }^{2}$ [el destacado y el subrayado son nuestros].

Ahora bien, lo anterior resulta totalmente ratificado por el contexto de las modificaciones que tuvo lugar en nuestro país a comienzos de la década de $1980^{3}$, particularmente por la reforma concretada en la Ley $N^{\circ} 18.175$ de 1982,

\footnotetext{
1 "[...] existe cierto grado de acuerdo en el sentido de que existen regulaciones legales especiales que incluyen, por su propia naturaleza, expresiones que van más allá de lo estrictamente legal, permitiendo que pueda replicarse a su respecto consideraciones provenientes de otras áreas, como lo pueden ser, las económicas. Una de dichas áreas se refiere al Derecho de Quiebras, en cuya evolución, la liquidación del activo del deudor-fallido, como una forma de retribución-sanción, ha dejado paso hacia la continuación de la empresa en insolvencia, en aquellos casos, en donde la permanencia de la actividad económica se justifica en razón de ciertas variables económicas, como es el caso de las empresas en crisis viables" (Núñez Ojeda, Raúl, y Carrasco Delgado, Nicolás, "La quiebra sin bienes. Una aproximación desde el análisis económico del derecho", Revista lus et Praxis, año 17, № 1, 2011, pp. 139-176, p. 144).

${ }^{2}$ Vid. Sentencia de la Excelentísima Corte Suprema de fecha 16 de marzo de 2011, dictada en los autos de quiebras Ingreso Corte No 5.755-2010. LegalPublishing: 48.183.

${ }^{3}$ Incluso con anterioridad, en el Mensaje de la ley $N^{\circ} 4.558$, de 1929, se expresa la necesidad de una ejecución expedita de la quiebra, se señala que: "El estado del deudor, sea o no comerciante, cuyo patrimonio hace muestra de un evidente desequilibrio entre su activo y su pasivo, no sólo perjudica el interés privado, sino que amenaza y compromete el interés público [...] lo que exige una liquidación
} 
Ley de Quiebras. De ahí que Antonio Skaric Carevic, ya a mediados de la misma década, identificara como criterios óptimos de una legislación de quiebras con miras a la eficiencia, la minimización de los costos asociados al proceso, la necesaria expedición del mismo, y una sana y ágil realización de los recursos ${ }^{4}$. Según la opinión del citado autor, la disminución de los costos de la quiebra se debía lograr a través de dos vías principales, a saber: (a) La minimización de los costos inherentes al sistema concursal, y (b) La minimización de los costos directos de la quiebra. Dichos objetivos se habrían logrado, en el marco de la ley $N^{\circ} 18.175$, con la eliminación de la Sindicatura de Quiebras. En efecto, en el sistema imperante bajo la vigencia de la ley $\mathrm{N}^{\circ} 4.558$ de 1931, se endilgaba a este órgano gran parte de la demora en el procedimiento, la cual ocasionaba pérdida de flujos económicos y, por tanto, menores tasas de recuperación crediticia. Asimismo, con la creación de síndicos privados y profesionales ${ }^{5}$, se otorgaba mayor flexibilidad al sistema, por la vía de la especialización del órgano administrador, generando así un ahorro para el Estado y una reducción de las probabilidades de error.

Reafirmando lo anterior, la última modificación sustantiva a la Ley de Quiebras vino dada por la dictación, en el año 2005, de las leyes $\mathrm{N}^{\circ}$ s. 20.004, y 20.073. Esta reforma tuvo su origen en la Agenda Pro-Crecimiento impulsada por el entonces Presidente de la República, don Ricardo Lagos Escobar. Para estos efectos, se constituyó una comisión técnica integrada por los señores Claudio Bonilla, Rafael Mery, José Tagle, Ronald Fischer, y Roldf Lüders ${ }^{6}$, quienes concluyeron lo siguiente:

"Creemos que es necesario hacer explícito un nuevo objetivo de la ley de quiebras. Este debería ser: 'Proveer el pago de las deudas de la manera más eficiente posible, decidiendo entre la conservación de la empresa viable y la liquidación eficiente y equitativa de la empresa no viable'. Con un objetivo así declarado se conjugan los conceptos de 'rehabilitación del deudor', presente en leyes como la americana, francesa o peruana, y el concepto de 'pago equitativo a los acreedores', presente en leyes como la chilena. El nuevo objetivo debiera ser

rápida de toda situación ruinosa de fortuna, a fin de evitar que se detenga, en manos inhábiles, la producción y la circulación de la riqueza".

${ }^{4}$ Skaric Carevic, Antonio, Reforma del sistema concursal chileno, sus fundamentos en el derecho internacional. Texto comparado de las Leyes $N^{\circ} 18.175$ y No 4.558, Memoria de prueba para optar al grado de Magíster en Derecho de la Contratación Comparada e Internacional, Facultad de Derecho Universidad de Chile, 1985, p. 4.

${ }^{5}$ Lo que se ha reforzado por medio de la dictación de la ley № 20.004 de 2005.

${ }^{6}$ BONILLA, Claudio; FISCHER, Ronald; LÜDERS, Rolf; MERY, Rafael; y TAGLE, José, "Análisis y Recomendaciones para una reforma de la ley de quiebras", Documentos de Trabajo del Centro de Economía Aplicada del Departamento de Ingeniería Industrial de la Universidad de Chile, 2004, № 191. 
el principio general que rija el contenido de la ley. [...] 'Una empresa es viable (conviene mantener su giro) si tiene utilidades operacionales no negativas y el valor presente de éstas es no inferior al valor de liquidación de la empresa'"17.

De esta forma, la eficiencia aparece claramente como un criterio normativo que inspira la totalidad de la legislación de quiebras. El propósito consiste en que el pago a los acreedores sea más eficiente, previa determinación del activo y del pasivo, y ya sea mediante la realización de aquél o mediante la rehabilitación del deudor.

Ahora bien, si se admite que la eficiencia cumple un rol normativo en la legislación de quiebras, entonces las herramientas y la metodología propias del análisis económico del Derecho resultan plenamente aplicables en esta área. Esto, toda vez que, desde su faz normativa, pretende que el ordenamiento jurídico pueda ser utilizado para la consecución de determinados fines, consistentes en la obtención de un resultado eficiente desde una óptica económica. Como efecto de la aplicación normativa señalada, resulta la posibilidad de utilizar herramientas metodológicas económicas con miras a la evaluación de las consecuencias de las decisiones judiciales ${ }^{8}$. Así las consecuencias de tales decisiones, en diversos escenarios de elección social, permitirán valorar en mayor medida $-y$, por tanto, facilitar la adjudicación en ese sentido- aquellas alternativas que tiendan a lograr el objetivo de elección socialmente deseable, que en este caso consiste en aplicar eficiencia para reducir los costos existentes en el proceso de quiebra, con miras a generar mayor recuperación crediticia. La normativa nacional que se describirá será enjuiciada con esos parámetros.

Por otro lado, si se acepta que la legislación de quiebras tiene un sustrato esencialmente procesal ${ }^{9}$-tal como sea ha sustentado en otra oportunidad ${ }^{10}{ }_{-}$, entonces los aportes del análisis económico del Derecho de quiebras, así como los del análisis económico del Derecho procesal, serán replicables a este respecto, según se verá a continuación.

\footnotetext{
7 Bonilla; Fischer; Lüders; Mery; y TAgle, "Análisis", cit. nota n. 6, pp. 4-5.

${ }^{8}$ Ver: Veljanovskı, Cento, Economía del Derecho, Trad. De La Maza, Íñigo y Mery, Rafael, Ediciones Diego Portales, Santiago, 2006, p. 57; y COASE, Ronald, "El problema del Costo Social", Revista de Estudios Públicos, № 45, 1992, p. 102.

${ }^{9}$ En lo relativo a la verificación, algunos autores la estudian desde consideraciones propiamente procesales: Puga VIAL, Juan Esteban, Derecho Concursal. El Juicio de Quiebras, $3^{\text {a }}$ ed. actualizada, Tomo II, Editorial Jurídica de Chile, Santiago, 2004, p. 366. En sentido contrario: Baeza Ovalle, José Gonzalo, “Naturaleza jurídica del proceso concursal", Revista Chilena de Derecho, Vol. 38, № 1, 2011, pp. 35-56.

${ }^{10}$ Carrasco Delgado, Nicolás, Análisis económico del derecho de la tutela cautelar. Aplicación a la legislación civil y de quiebras en Chile, Tesis para optar al grado de Magíster en Derecho con mención en Derecho Económico, Escuela de Graduados Facultad de Derecho Universidad de Chile, 2011, pp. 285-293.
} 
Pues bien, el análisis económico del Derecho analiza, en relación con el Derecho de quiebras, las decisiones vinculadas con la quiebra desde dos perspectivas ${ }^{11}$, a saber: (a) Eficiencia ex ante, que permite evaluar la decisión de una empresa existente y que no se encuentra en dificultades, respecto de las posibilidades de realizar un proyecto adicional, de carácter arriesgado. La quiebra, desde este enfoque, sería una consecuencia de una errada decisión de contratación financiera, y (b) Eficacia ex post, que sirve para decidir cuándo una decisión entre liquidación y continuación de la empresa resulta beneficiosa socialmente, tratándose de una empresa que carece de liquidez y que sólo puede subsistir con financiamiento adicional.

La distinción efectuada anteriormente es útil para delimitar los ámbitos de estudio que se relacionan con cada perspectiva de eficiencia. Así, la eficiencia ex ante forma parte de la problemática de las finanzas corporativas ${ }^{12}$; en cambio, la eficiencia ex post se relaciona con lo propiamente concursal, porque supone una elección frente al problema de la insolvencia, cuya concreción se verifica dentro del proceso de quiebra. En atención a lo anterior, el presente acápite se centrará en la segunda clase de eficiencia.

Esto conduce a señalar que el sistema de quiebras, como procedimiento especial, tiende a un objetivo adicional a las dos finalidades tradicionales del análisis económico del Derecho procesal ${ }^{13}$, consistente en la generación de la mayor cantidad de riqueza posible en el marco del sistema de quiebras. Este es un propósito pacíficamente aceptado en la doctrina ${ }^{14}$, y para su consecución no sólo basta la manera en que la ley enfrente la insolvencia o la iliquidez. En efecto, extiende sus implicancias a las decisiones adoptadas por la empresa en el periodo previo a la crisis y, por tanto, al momento de la valoración de las decisiones corporativas de acuerdo a un parámetro de eficacia concursal ex ante. En otras palabras, una empresa llega a una situación de insolvencia cuando fracasan uno o más de los proyectos desarrollados por ella y, a consecuencia de ello, la empresa adquiere un valor económico negativo que además le imposibilita seguir haciendo frente a sus acreedores. Pues bien, la valoración

\footnotetext{
${ }^{11}$ GrISSKopf, Ofer, y MeDInA, Barak, Repairing (the Doctrine of) Irreparable Harm: Economic Analysis of Preliminary Injunctions, 2008, pp. 21-22. Disponible en http://works.bepress.com/barak_medina/6 [visitado el 20/12/2011].

${ }^{12}$ Wohlschlegel, Ansgar, The EConomics of Corporate Bankruptcy Law, 2002, p. 28. Disponible en http://archiv.ub.uni-heidelberg.de/volltextserver/volltexte/2002/3087/pdf/DissVeroeff.pdf [visitado el 20/12/2011].

${ }^{13}$ Que, como se verá más adelante, se trata de la reducción de dos clases de costos, esto es, el costo del error judicial y el costo del procedimiento.

${ }^{14}$ LeubSDORf, John, "The Standard for Preliminary Injuctions", Harvard Law Review, 1978 (№ 91), p. 1; Y WOHLSCHLEGEL, cit. nota n. 12, pp. 18 y 21.
} 
acerca de la rentabilidad de un determinado proyecto, es una actuación que se realiza por la empresa antes de caer en situación de falencia, y es propia de las tareas financieras de cada negocio. Por tanto, si se llega a una situación de falencia, es porque existió una ineficacia concursal ex ante, esto es, una errada valoración de la rentabilidad de uno o más proyectos determinados.

Sin que sea necesario profundizar mayormente en dicha materia, que es propia de los estudios de economía y de ingeniería comercial, es posible agregar que la rentabilidad de un determinado proyecto va a aumentar de acuerdo al juego de una serie de variables, siendo la primera de ellas que el financiamiento sea obtenido con las menores tasas de interés posibles, precisamente porque el rendimiento neto se incrementa cuando caen los costos de financiamiento. Adicionalmente, el éxito del proyecto es una función positiva del nivel de esfuerzo de la empresa y de una variable de los estados estocásticos, esto es, de consideraciones exógenas a la preocupación de los administradores. De esta forma, a medida que se aumenta el esfuerzo empresarial por el éxito de un proyecto, se incrementa asimismo la probabilidad de un resultado favorable. Desde el punto de vista de la eficiencia, la empresa hará todos los esfuerzos posibles hasta que su ganancia marginal se iguale al costo marginal, es decir, hasta que el beneficio que se obtiene de un peso adicional de esfuerzo sea superior a dicho gasto. Sin embargo, dado que el resultado del esfuerzo llevado a cabo no retribuye solamente a la empresa, sino también a los acreedores financistas, entonces no existirá incentivo para realizar el esfuerzo óptimo, sino que los administradores elegirán un nivel de esfuerzo menor. De este modo, el resultado del conjunto de las variables indicadas llevará a establecer un determinado nivel de activos sobre el cual los acreedores podrán satisfacer sus pretensiones, lo que permite concluir que dicha etapa tiene una gran relevancia para la suerte del proceso concursal, en cuanto se refiere a su finalidad de maximizar la rentabilidad de los acreedores.

Ahora bien, el objetivo del análisis económico del Derecho concursal, tendiente a maximizar el beneficio de los acreedores, que se traduce en una mayor tasa de recuperación de sus créditos, concurre conjuntamente, como hemos dicho, con los objetivos tradicionales del análisis económico del Derecho procesal. En efecto, de acuerdo a la literatura del análisis económico del Derecho procesal, los objetivos que deben buscarse en dicha área jurídica involucran la reducción de dos clases de costes, a saber: la reducción de los costos del sistema judicial y la reducción de los costos del error ${ }^{15}$. Desde dicha perspectiva, una

${ }^{15}$ CoOter, Robert y Ulen, Thomas, Derecho y Economía, Fondo de Cultura Económica, México, DF, 1998, pp. 530-532; y POsner, Richard, El análisis económico del Derecho, Fondo de Cultura Económica, México, DF, 1992, pp. 549-551. 
solución eficiente sería aquella que ponderara ambas clases de costes, ya que de esta manera se obtendría una respuesta óptima. Lo anterior, precisamente, porque el sistema de quiebra, desde la perspectiva de su naturaleza jurídica, constituye un extensión del Derecho procesal.

Respecto del objetivo de reducción de los costos que genera el error, es importante puntualizar que, en materia de Derecho concursal, se modifica el sentido de dicha finalidad, ya que aquí no se pretende lograr un nivel de adecuación probabilístico entre la efectividad de las pretensiones de partes con intereses contrapuestos y aquello que pueda ser resuelto en una sentencia definitiva. En efecto, lo que se busca es elegir aquella opción de satisfacción a los acreedores (liquidación o reorganización) que genere la mayor cantidad de beneficios posibles maximizando la utilidad de los partícipes en el proceso. En otros términos, se medirá la reducción del error y la corrección del sistema, en la medida que éste genere la mayor recuperación de créditos a sus legítimos propietarios, lo que se producirá cuando se opte por la alternativa que maximice el valor de las reclamaciones en contra del fallido. Así, la eficacia concursal ex post está inversamente relacionada con el coste del error en materia de quiebras.

En cuanto al objetivo de reducción de costes del sistema concursal, existe una primera discusión relativa a aquello que debemos considerar como costo del proceso de quiebra. Al respecto, a partir del teorema Modigliani-Miller ${ }^{16}$, las ineficacias generadas en el marco de un proceso de quiebra daban origen a costos que debían considerarse al momento de determinar la estructura de capital financiera de una empresa. De esta manera, la quiebra no sólo producía costes, por así decirlo, directos (gastos derivados del litigio procesal; consignaciones; multas; gestión de órganos concursales; pérdida de valor de activos por desuso; etc.), sino que también costos indirectos, que se encontraban presentes incluso antes de producida la insolvencia. Posteriormente, y a partir de las contribuciones de Haugen y Senbet ${ }^{17}$, se concluyó que estos costes eran irrelevantes para la determinación de la estructura de capital de una empresa, y consecuencialmente generan poco impacto sobre los precios de los créditos anteriores a la quiebra. En base a lo anterior, es posible identificar como costos del sistema concursal aquellos que se producen en la mecánica y prosecución del procedimiento de quiebras. No se incluyen dentro de éstos las ineficiencias generadas por costos de oportunidad en la elección de un determinado

\footnotetext{
${ }^{16}$ Ver: Modigliani, Franco, y Miller, Merton, The Cost of Capital, Corporation Finance, and the Theory of Investment, American Economic Review, № 48, 1958, pp. 261-297; ModigliANI, Franco, y MiLleR, Merton, Corporate Income Taxes and the Cost of Capital, American Economic Review, № 53, 1963, pp. 433-443.

17 Haugen, Robert, y Senbet, Lemma, Bankruptcy and Agency Costs: Their Significance to the Theory of Optimal Capital Structure, Journal of Financial and Quantitative Analysis, № 23, 1988, pp. 27-38.
} 
mecanismo concursal (que, como se ha señalado, se traducen en un costo de error), ni gastos que reduzcan la rentabilidad de los acreedores en razón del financiamiento más caro al que se pudo acceder por el riesgo de la insolvencia. Respecto de los costos directos de la quiebra, que son los aquí importan, ellos guardan armonía con la expedición del proceso. De esta forma, el factor tiempo ayudará a reducir los costos del sistema, sin que por otra parte genere una disminución de la eficiencia concursal ex post, en la medida en que se respeten los tiempos óptimos para arribar a una decisión de elección de mecanismo de satisfacción a los acreedores, con carácter técnico.

De esta manera, lo que en este trabajo interesa es la eficacia ex post, toda vez que la adopción de la decisión de liquidar el patrimonio en falencia debe suponer una opción socialmente beneficiosa, que vendrá dada por la obtención de la mayor tasa de recuperación crediticia posible. En dicho escenario, la reducción de los costos de la quiebra permite aumentar la tasa de recuperación de créditos. Por lo tanto, cualquier reforma en tal sentido resulta deseable, máxime si ello no solamente significa reducción de los tiempos de tramitación de las quiebras -que en nuestro país son excesivos-, sino que además se traduce en asignar las funciones legales en los órganos que poseen mejor competencia para llevar a cabo las atribuciones respectivas.

Por lo mismo, se hace presente que las críticas que se formularán en este trabajo, se basan en consideraciones de análisis económico del Derecho tendientes a unificar el tratamiento de las etapas de verificación de créditos y de realización de activos, con el fin de eliminar regulaciones normativas que encarecen y ralentizan la tramitación de la quiebra. En otras palabras, se pretende reducir aquellos costos identificados por las investigaciones de Haugen y Senbet, y con ello posibilitar una mayor tasa de recuperación de créditos, en el entendido que a medida que disminuyen los costos del proceso de quiebra y se reduce el margen de error -por medio de una asignación óptima de la facultad decisoria-, existe una mayor tasa de reintegro crediticio. Resulta importante constatar que la necesidad de incorporar un tratamiento desde la Economía de la Ley se debe a que, a pesar del objetivo de eficiencia que ilustra la normativa sobre falencia, el análisis de datos sobre las quiebras en Chile demuestra la existencia de un procedimiento lento, caro y con escasa rentabilidad para los acreedores que verifican sus créditos en el proceso.

Es así como se pretende mejorar los índices de lo que hemos denominado eficacia concursal ex post, que se vincula directamente con la decisión de disposición en el contexto de un proceso de liquidación del patrimonio desasido. La descripción de la normativa tendrá por objeto detectar aquellas regulaciones que atentan contra dicho objetivo de eficacia, para posteriormente proponer una reforma en base a ciertos criterios normativos que se extraerán, en parte, de experiencias exitosas del Derecho comparado, precisamente de aquellas 
legislaciones que han demostrado una alta tasa de recuperación crediticia y que han tenido en vista especialmente la necesidad de mejorar tal índice de retorno.

Lo que se ha señalado en forma más bien resumida, a propósito de los criterios del análisis económico del Derecho de quiebras y procesal, servirá adicionalmente como pauta de interpretación de nuestra normativa sobre quiebras, frente a la dispersión de criterios y disimilitud de pronunciamientos de nuestros tribunales de justicia ${ }^{18}$. En efecto, el criterio de eficiencia con miras a generar una mayor eficacia concursal ex post, constituye un instrumento propiamente normativo que sirve al ejercicio de la decisión jurisdiccional, según se ha explicado.

\section{Regulación nORMAtiva sObre la Verificación de CRÉDitos y la ReAlizACIÓN DE ACtivos, Y SU INTERDEPENDENCIA}

\section{Generalidades}

La regulación de quiebras en nuestro país está afecta a dos grandes dificultades, a saber: (a) Lentitud del procedimiento, y (b) Duplicidad de funciones de los órganos de la quiebra, o bien, atribución ineficiente de las funciones que a ellos competen.

En relación con la lentitud del proceso, en el presente trabajo se examinará la normativa de quiebras especialmente a propósito de la verificación de créditos y la realización del activo. Como se ha indicado anteriormente, la perspectiva para analizar la quiebra, es aquella propia del Derecho procesal ${ }^{19}$. Además, dado que la eficiencia constituye un criterio normativo de interpretación, resultan plenamente aplicables las consideraciones que podamos extraer del análisis económico del Derecho (law and economics) ${ }^{20}$.

En cuanto a la verificación de créditos, cabe resaltar que la misma sirve tanto para determinar los acreedores que podrán participar en el reparto o pago que se generará a raíz de la quiebra, como también para efectos de conocer qué acreedores pueden participar en las juntas de acreedores. Por su parte, la realización de bienes constituye el procedimiento ejecutivo tendiente a liquidar el patrimonio en falencia. Con su producto se hará pago a los acreedores cuyos créditos hayan sido reconocidos en el procedimiento de verificación. De esta forma,

\footnotetext{
${ }^{18}$ Torres ZAGAL, Óscar, "Naturaleza jurídica de la resolución que resuelve sobre impugnación de crédito en el juicio de quiebra", Gaceta Jurídica, № 243, año 2000, pp. 11-13, p. 11.

${ }^{19}$ Carrasco Delgado, Análisis, cit. nota n. 10, pp. 180-188.

${ }^{20}$ Núñez Ojeda, y Carrasco Delgado, "La quiebra", cit. nota n. 1, pp. 142-146.
} 
ambas etapas del proceso de quiebras se encuentran perfectamente entrelazadas: La verificación sirve para saber a quiénes, y con qué preferencia, se pagará con los resultados de la realización del activo. Esta vinculación ineludible entre ambas etapas, genera una importante consecuencia: No resulta posible reducir los tiempos de tramitación del proceso de quiebras eliminando las deficiencias y obstáculos de tiempo de la verificación de créditos, si es que no se resuelven idénticos problemas a propósito de la realización del activo, y viceversa. Por esa razón, entonces, se estudian conjuntamente en este trabajo.

Ambos, también, son antecedentes necesarios de la cuenta definitiva que debe rendir el síndico, la que constituye el acto de administración final de su actuación en la quiebra. De hecho, de conformidad con el Instructivo $\mathrm{N}^{\circ}$ 9 de la Superintendencia de Quiebras ${ }^{21}$, en la cuenta final de administración se debe incorporar todo lo relativo al pago de los acreedores, lo que supone indudablemente que el proceso de verificación y de realización del activo ha culminado completamente.

El problema de lo anterior es que la regulación sobre verificación y realización de activos no tiende actualmente a la eficiencia, específicamente en lo relativo a la reducción de los costos del proceso de quiebra; y, por otro lado, que la serie de trámites existentes -fundamentalmente a propósito de la verificación- no se traduce en la consecución de una reducción de los costos del error judicial (como podrían ser una errada determinación de los créditos reconocidos; una equivocada graduación de las preferencias; o bien, vicios formales en la ejecución del patrimonio concursado).

Como contexto general de lo señalado precedentemente, cabe señalar que el Banco Mundial ${ }^{22}$ ha informado que el promedio de duración de los proce-

\footnotetext{
${ }^{21}$ Específicamente, artículo $5^{\circ}$ del Instructivo № 9 de la Superintendencia de Quiebras, de fecha 29 de diciembre de 2009, donde se establece que dentro de los egresos se debe contemplar los repartos de fondos.

22 "La ley de insolvencia establece un procedimiento de liquidación de quiebra tradicional, el cual es en la práctica bastante ineficiente. Los procedimientos de quiebra abarcan todos los activos y obligaciones del deudor (incluso obligaciones no del pasado), excepto aquellos activos y obligaciones expresamente excluidas por ley (ejemplo: hipotecas o activos en prenda). La adjudicación de quiebras tiene certeza inmediata y efecto retroactivo. La realización de un estado de quiebra, en teoría, debería ser prontamente completada de modo de satisfacer los requerimientos de los acreedores con las ganancias obtenidas. En la práctica, sin embargo, las liquidaciones son procesos largos. Su promedio de duración es 24 a 36 meses. Una vez las reclamaciones privilegiadas y garantizadas son pagadas, los acreedores no garantizados (acreedores valistas o sin privilegio) típicamente reciben porcentajes de distribución muy bajos" (Banco Mundial, Informe sobre Observancia de Estándares y Códigos, Chile, Junio 2004, párrafo 15. Disponible en http://www-wds.worldbank.org/external/default/main?menuPK $=64187510 \&$ pagePK $=64193027 \&$ piPK $=64187937 \&$ theSitePK $=523679 \&$ menuPK $=64154159 \&$ search MenuPK=64258544\&theSitePK=523679\&entityID=000160016_20060126181835\&searchMenuPK=6 4258544\&theSitePK=523679 [visitado el 20/03/2012]).
} 
sos de quiebra en Chile alcanza los 48 meses. A resultados similares arribaron los estudios técnicos que precedieron a la dictación de las leyes № 20.004 y $\mathrm{N}^{\circ} 20.073^{23}$. El estudio internacional más reciente sobre la materia, lo constituye el ranking "Doing Business" ${ }^{24}$, donde consta que las quiebras en Chile poseen una tramitación promedio de 4 años y 5 meses, constituyendo el sistema más lento de América Latina luego de Ecuador (cuyo plazo promedio es de 5 años y 3 meses). Se aprecia, entonces, la crítica situación en que se encuentra la legislación nacional, máxime si se considera que la duración promedio de la tramitación en los distintos sistemas analizados de 3 años y $1 \mathrm{mes}^{25}$. Más específicamente, las cifras chilenas están muy lejanas del lapso de 1 año y 3 meses que demora un proceso de quiebras en Colombia, o del plazo de 1 año y 8 meses en Bolivia, o de los 2 años y 1 mes que dura en Uruguay ${ }^{26}$. El promedio de tramitación de los países de la OECD es de 1 año y 7 meses, constituyendo Chile el sistema más lento de todos aquellos que forman parte de la mencionada Organización Internacional.

En cuanto a los costos del sistema de quiebra, el ranking mencionado establece la medición como un porcentaje del patrimonio materia de la quiebra. El porcentaje del sistema chileno alcanza el $15 \%$, lo que en el contexto general de Latinoamérica ubica al país bajo el promedio que alcanza 11,4\%. Chile solamente supera a Ecuador (18\%), e iguala a Bolivia (15\%). Respecto de los países de la OECD, nuevamente es el país en peor situación, ya que el promedio de aquéllos alcanza el 9\%.

La situación mejora levemente en relación con las tasas de recuperación de créditos, ya que de 9 sistemas analizados, Chile se ubica en el sexto lugar, con un porcentaje de $25,5 \%$ de los créditos reconocidos (supera a Brasil, que cuenta con un $17,1 \%$; a Ecuador que obtiene un $17,2 \%$, y a Paraguay que posee un $16,6 \%$ ). Aunque se encuentra muy lejano aún del $68,2 \%$ que promedian los países de la OECD, está más cercano del promedio de 33,6\% correspondiente a los nueve países analizados en Latinoamérica.

Las peores ineficiencias de la normativa analizada recaen sobre realización de activos y verificación de créditos, toda vez que consagran trámites y etapas

\footnotetext{
${ }_{23}$ "Para medir el tiempo de demora el proceso de quiebras de una empresa se contó en meses el tiempo transcurrido desde la declaración de quiebra hasta la publicación de la última resolución, encontrando un plazo promedio de 40,7 meses y una desviación estándar de 20,9 meses. Estos datos provienen de nuestra muestra de 32 empresas" (Bonilla; Fischer; Lüders; MerY; y Tagle, "Análisis", cit. nota n. 6, p. 77).

${ }^{24}$ Banco Mundial, Doing Business. Disponible en http://www.doingbusiness.org/data/exploretopics/ resolving-insolvency [visitado el 23/12/2011].

${ }^{25}$ Se analizaron 9 sistemas correspondiente a los siguientes países: Argentina; Bolivia, Brasil; Colombia, Chile; Ecuador; Perú; Uruguay, y Paraguay.

${ }^{26}$ A nivel mundial, los sistemas más eficientes en cuanto a tiempo son Irlanda, con 4 meses de tramitación; Japón, con 6 meses, y Canadá y Singapur, con 8 meses.
} 
que pueden ser fácilmente remplazadas, y a muy bajo costo, asignando las funciones a los órganos mejor capacitado para dichos efectos, lo que permitiría reducir la tramitación en cuanto a tiempo y bajar los costos. Sin embargo, parte importante de las mejoras en las tasas de recuperación, requieren de reformas sustanciales vinculadas principalmente con el régimen de garantías. El Derecho procesal puede contribuir en los dos primeros aspectos.

A continuación, en esta sección, analizaremos brevemente la forma en que nuestra legislación ha abordado las dos etapas procesales materia de este trabajo: la verificación de créditos y la realización de activos. También se indicarán las deficiencias de esta normativa.

\section{La verificación de créditos}

\subsection{Introducción}

La sentencia que declara la quiebra de una persona produce sus efectos de inmediato y deberá contener, de conformidad a lo dispuesto en el artículo 52 $N^{\circ} 6$ y 7 LQ, la orden de llamamiento a todos los acreedores del fallido, residentes en el territorio de la República, o bien que se hallen fuera de la República, para que concurran al tribunal de la quiebra a verificar sus créditos en las condiciones y bajo los supuestos que las normas anteriores señalan. De esta forma, se otorga existencia práctica al principio de la generalidad, en virtud de la cual la quiebra se desarrolla frente a todos los acreedores del fallido, salvo las excepciones legales. El objetivo de la verificación de créditos es el reconocimiento de los acreedores en su calidad de tales, a través de los procedimientos y formas que la ley establece ${ }^{27}$.

El artículo $2^{\circ}$ de la Ley de Quiebras dispone: "La quiebra produce para el fallido y todos sus acreedores un estado indivisible. Comprenderá, en consecuencia, todos los bienes de aquél y todas sus obligaciones aun cuando no sean de plazo vencido, salvo aquellos bienes y obligaciones que la ley expresamente exceptúe". El estado indivisible que nace de la declaración de quiebra implica consecuencias para el fallido y para los acreedores. Los efectos que se producen respecto del fallido están sintetizados en los efectos inmediatos de la declaración de quiebra, que se regulan en los artículos 64 a 73 LQ. En cambio, con respecto a los acreedores, se da origen a la masa de acreedores, que no tiene vida propia ni constituye un patrimonio separado, sino que consiste en la unión teórica que

\footnotetext{
${ }^{27}$ En este mismo sentido, se ha resuelto por la jurisprudencia que: "La verificación de créditos es normalmente un procedimiento en virtud del cual un acreedor sostiene una pretensión de cobro en contra de un deudor. Se persigue un reconocimiento de la existencia de la respectiva acreencia". Vid. Sentencia de fecha 23 de diciembre de 2004, dictada en los autos sobre quiebras, Ingreso Corte № 320-2003, LegalPublishing: 31.628.
} 
se produce, como consecuencia de la quiebra, entre todos aquellos acreedores que son titulares de créditos con derecho a participar en la quiebra del fallido. Dicha participación dice relación con dos aspectos y consecuencias ${ }^{28}$, a saber:

a) Es importante para efectos de determinar quiénes participan en los repartos de fondos, en qué momento y con qué preferencia, y

b) Es importante para efectos de saber qué acreedores pueden participar con derecho a voto en las reuniones de la junta de acreedores, que constituye el órgano de la quiebra que reúne a la masa de acreedores.

A continuación, se desarrollará lo relativo al procedimiento de verificación de créditos, para luego analizar de qué manera la legislación nacional regula las consecuencias relevantes de la verificación señaladas precedentemente.

\subsection{Explicación del procedimiento de verificación y sus clases}

Debe indicarse que, históricamente en Chile, el proceso de verificación pasó de estar configurado en base a audiencias verbales (juntas de verificación ${ }^{29}$ ) a ser un procedimiento fundamentalmente escrito ante el juez de la quiebra.

Actualmente, la ley establece que todos los acreedores residentes en el territorio de la República, sin excepción alguna, tendrán el plazo de treinta días, a contar de la notificación de la declaración de quiebras, para verificar sus créditos y alegar sus preferencias ante el tribunal que conozca de ella (artículo 131 LQ). Se ha declarado que el crédito debe ser dinerario, justificado documentalmente ${ }^{30}$ y anterior a la quiebra ${ }^{31}$. Misma obligación rige para los acreedores que suministren servicios de utilidad pública en los términos indi-

\footnotetext{
${ }^{28}$ En este sentido, la Guía Legislativa sobre el Régimen de la Insolvencia, elaborada por la Uncitral, señala que las demandas o solicitudes que los acreedores efectúen respecto de sus créditos son relevantes, por una parte, para determinar qué acreedores podrán tener derecho a voto y de qué manera lo podrán ejercer; y, por otra, para efectos de la distribución. Su texto en español se encuentra disponible en http://www.uncitral.org/pdf/spanish/texts/insolven/05-80725_Ebook.pdf [visitado el 20/03/2012].

${ }^{29}$ Efectivamente durante la vigencia del Código de Comercio, el síndico citaba a una junta de verificación a los acreedores, quienes debían concurrir con sus títulos y minutas de verificación, o bien, sin éstos, pero anunciando sus medios de prueba. Se procedía a la revisión de cada crédito, y en caso de existir impugnaciones, el juez las resolvía en la misma audiencia, salvo que se recibiera la causa a prueba. Sobre el sistema existente en la estructura del Código de Comercio, ver: PuGA VIAL, Juan Esteban, Derecho Concursal. El Convenio de Acreedores, Editorial Jurídica de Chile, Santiago, 1997, pp. 192 y ss.

${ }^{30}$ A este respecto, el artículo 133 de la Ley de Quiebras, al exigir la necesidad de acompañar los títulos justificativos, ha pretendido señalar que cualquier documento que tenga la capacidad de acreditar la existencia de la deuda cumplirá el objetivo de dar cuenta de su existencia. En este sentido, Vid. Sentencia de la Excelentísima Corte Suprema de fecha 21 de enero de 2010, dictada en los autos sobre quiebras, Ingreso Corte No 7.232-2008, LegalPublishing: 43.113.

31 Vid. Sentencia de la Excelentísima Corte Suprema de fecha 21 de enero de 2010, dictada en los autos sobre quiebras, Ingreso Corte Nº 7.232-2008, LegalPublishing: 43.113.
} 
cados en el artículo $132 \mathrm{LQ}^{32}$, así como también respecto de los acreedores que se hallen fuera del territorio de la República en los términos indicados en los artículos 139 y 52 Nº 7 LQ.

Estas verificaciones de crédito deben contener lo que se les debe a los acreedores por concepto de capital e intereses. Asimismo, deben acompañar los títulos justificativos de sus créditos, para efectos de que sea anunciada la verificación (artículo 134 LQ), y así posibilitar el examen del síndico (artículo 135 LQ) y las impugnaciones que pudieran deducirse por no haberse encontrado justificado el crédito o la preferencia reclamada (artículos 135 inciso $2^{\circ}$ y 137 LQ). También, para que el síndico efectúe reserva con respecto a alguno de los créditos verificados, para efectos de impedir la preclusión de una eventual impugnación al crédito por transcurso del plazo legal para impugnar, de acuerdo a lo señalado en el artículo 138 inciso $2^{\circ}$ LQ. A costa de la masa, se mandará anunciar por aviso (notificación por el Diario Oficial), los créditos que se presente a la verificación ${ }^{33}$ (artículo 134).

El síndico deberá hacer un prolijo examen de los créditos que se presenten a la verificación y de las preferencias alegadas, investigando su origen, cuantía y legitimidad por todos los medios a su alcance. En el evento de no encontrar justificado el crédito o la preferencia alegada, deberá deducir demanda de impugnación respecto del crédito o preferencia (artículo 135 LQ). Sobre esta demanda se ha señalado que:

"La impugnación de crédito es un juicio, una contienda entre partes que comprende aspectos de hecho y de derecho que deben ser conocidos y resueltos

\footnotetext{
${ }^{32}$ La norma consagra un precepto muy importante, por cuanto, aquellos acreedores que suministren servicios de utilidad pública, como gas, luz, y agua, no pueden suspender el suministro sin previa autorización del tribunal, con lo cual se posibilita la continuidad de servicios fundamentales para la marcha de la actividad económica de la empresa en falencia. El artículo 132 inciso $2^{\circ}$ LQ establece que los créditos correspondientes a servicios de utilidad pública que se suministren con posterioridad a la declaratoria de quiebra, se considerarán incluidos en el № 4 del artículo 2472 del Código Civil. El inciso $3^{\circ}$ del artículo 132 introduce una regulación infraccional de difícil conceptualización, al disponer que la suspensión del servicio en contravención a lo señalado anteriormente, se considerará como un acto que tiende a impedir la libre competencia, que será sancionado con arreglo al DL $N^{\circ} 211$. Lo extraño de la mencionada regla es que determina una vulneración meramente infraccional, ya que se podría concluir que por el solo hecho de suspender un servicio de utilidad pública, sin autorización del tribunal y con previa audiencia al síndico, se estaría infringiendo la libre competencia, aun cuando no exista análisis de aptitud, daño anticompetitivo, poder de mercado, o mercado relevante.

${ }^{33}$ Tal como señala nuestra jurisprudencia, el hecho que la ley fije un plazo a los acreedores para que verifiquen sus créditos, es sólo para efectos de que los acreedores que hagan sus verificaciones dentro del plazo señalado gocen de algunos beneficios de que no gozarán los que verifiquen sus créditos en forma extraordinaria. En ningún caso hace precluir el derecho para verificar créditos en este último carácter. En este sentido, Vid. Sentencia de la Excelentísima Corte Suprema de fecha 7 de diciembre de 2009, dictada en los autos sobre quiebras, Ingreso Corte No 4.046-2009, LegalPublishing: 43.510.
} 
por el juez de la quiebra, a quien, si bien la ley encomienda realizar en un solo procedimiento los bienes de un sujeto para proveer al pago de sus deudas, no por ello conoce de un solo juicio sino de todos los que sea menester para la consecución del declarado propósito [... $]^{\prime \prime 34}$.

El síndico, los acreedores y el fallido podrán interponer demanda de impugnación contra los créditos, desde el momento en que se haya agregado a los autos la respectiva solicitud y hasta quince días después de notificada la resolución que da por cerrado el procedimiento de verificación. El síndico y los acreedores podrán deducir demanda de impugnación ${ }^{35}$, también dentro del mismo plazo, en contra de las preferencias reclamadas, no contemplándose dicha posibilidad al fallido, a quien no le es de incumbencia la preferencia con que los acreedores deben pagarse ${ }^{36}$ (artículo 137 LQ) ${ }^{37}$.

Los créditos no impugnados dentro del plazo señalado anteriormente tendrán el carácter de reconocidos y no podrán ser objeto de impugnación posterior, a menos que a su respecto haya existido una reserva de impugnación por parte del síndico, en tal caso existirá un plazo adicional para impugnar de diez días (artículo 138 LQ).

Cada impugnación se tramitará en cuaderno separado, sin perjuicio de las acumulaciones que procedan. La demanda de impugnación se notificará al demandado personalmente o en la forma prescrita en el artículo 44 del Código de Procedimiento Civil, el que dispondrá de seis días fatales para responder. En lo demás, se aplicará el procedimiento incidental general en materia de quiebras, contemplado en el artículo $5^{\circ}$ inciso $1^{\circ} \mathrm{LQ}$ (artículo $141 \mathrm{LQ)}$ ). El síndico podrá intervenir como parte coadyuvante en toda impugnación, cuando no figure

\footnotetext{
${ }^{34}$ Vid. Sentencia de la Excelentísima Corte Suprema de fecha 6 de noviembre de 1997, dictada en los autos sobre quiebras, Ingreso Corte No 491-1997, LegalPublishing: 14.943.

${ }^{35}$ En efecto, "por ser el patrimonio una garantía común, sobre la cual actuarán pluralidad de pretensiones, será menester que los acreedores encuentren respuestas técnicas que les permitan el recíproco control de las incorporaciones crediticias al estado concursal" (Garaguso, Horacio y Medina, María Rosa, Verificación de Créditos en los Países del Mercosur, Ad-Hoc, Buenos Aires, 1998, p. 24).

36 "Este régimen expone con evidencia los alcances de la concursalidad del proceso y particularmente de la verificación de créditos, toda vez que el grado o privilegio es reconocido ante el deudor pero "contra los acreedores". Es por ello que la situación deviene en indiferencia para el fallido pero más que trascendente para los acreedores y eventualmente para el síndico, el que debe velar por una legítima asignación de grado, en función de la regla de los arts. 147 y 148 de la Ley de Quiebras" (Garaguso y Medina, Verificación, cit. nota n. 35, p. 108).

${ }^{37}$ En el caso de los créditos subordinados, las demandas de impugnación relacionadas con tales créditos solamente podrán ser ejercidas por los acreedores afectados por tal subordinación. Ahora bien, la ley es clara en señalar que la demanda de impugnación referida a una subordinación no impide el reparto a los demás acreedores comunes no comprendidos en la subordinación (artículo 137 inciso $\left.2^{\circ} \mathrm{LQ}\right)$.
} 
como parte principal. Velará, en todo caso, porque el procedimiento siga su curso, sin dilaciones (artículo 142 LQ).

Al tribunal le corresponde resolver las demandas de impugnación que se presenten en contra de los créditos verificados en el periodo ordinario de verificación, tratándose tanto de los acreedores residentes en el territorio de la República (artículo 136 LQ), como de aquellos residentes fuera del territorio de la República (artículo 139 LQ). Asimismo, debe conocer de las impugnaciones en contra de los créditos de aquellos acreedores que no hayan verificado oportunamente sus créditos o preferencias (artículo 140 LQ) ${ }^{38}$. Se ha sostenido que la sentencia que resuelve una impugnación tiene el carácter de sentencia definitiva y, por lo tanto, debe notificarse por cédula y personalmente ${ }^{39}$. En efecto, se ha afirmado que la verificación es una cuestión de naturaleza principal, cuya finalidad es satisfacer los fines de la quiebra, descartando su naturaleza incidental y, por tanto, la naturaleza jurídica de interlocutoria de la resolución que la falla. Sin embargo, definir la tramitación de la objeción de una verificación como un proceso principal, además de aumentar los costos asociados (mayores formalidades de notificación, trámites y recursos de más lenta resolución), no se aviene con el proceso de quiebras, que contempla una tramitación incidental para toda cuestión accesoria (artículo $5^{\circ}$ inciso $1^{\circ} \mathrm{LQ}$ ), Dicha posición genera graves inconsistencias en la doctrina, que trata de explicar de manera algo contradictoria la naturaleza de este proceso ${ }^{40}$.

Una vez vencidos los términos de emplazamiento para los acreedores residentes en el territorio nacional y en el extranjero, el juzgado de oficio o

\footnotetext{
${ }^{38}$ En la verificación ordinaria, el síndico, los acreedores, y el fallido, podrán interponer demanda de impugnación contra los créditos y preferencias reclamadas, desde el momento en que se haya agregado a los autos la respectiva solicitud, y hasta quince días después de notificada la resolución que da por cerrado el procedimiento de verificación (artículo 137 LQ). En el tercer caso, las impugnaciones deben deducirse dentro de quince días, contados desde la notificación por aviso a los acreedores, y por cédula al síndico, de los créditos de los acreedores que no hayan verificado oportunamente (inciso $2^{\circ}$ del artículo 140 LQ).

${ }^{39}$ En este sentido: Torres Zagal, Naturaleza, cit. nota n. 18, pp. 12-13, y Puga Vial, Derecho Concursal, cit. nota n. 9, p. 413. Este último autor señala que en la impugnación se discute el derecho de cada acreedor singular de incorporarse al juicio de quiebras principal.

${ }^{40}$ En este sentido, Puga Vial dedica algunos pasajes de su libro sobre Derecho Concursal a la determinación de la naturaleza de la tramitación de la verificación. Al respecto, señala que se trataría de una acción ejecutiva colectiva, aun cuando debe reconocer que no es dirigida contra quien posee una obligación debida (el deudor), y que no existe un título ejecutivo (que es de la esencia de todo proceso ejecutivo), debiendo además aceptar que el calificativo de colectiva resulta bastante forzado, ya que no existe litis consorcio pasiva o activa de carácter necesaria. Adicionalmente, si es que la verificación tiene por objeto debatir el derecho de cada acreedor a participar de la ejecución, entonces lo que se pretende es una declaración que genere tal habilitación, lo que no se aviene precisamente con un juicio ejecutivo. Resulta difícil concebir, como lo hace tal autor, que un asunto accesorio no sea un incidente, sino un juicio autónomo (Puga VIAL, Derecho Concursal, cit. nota n. 9, pp. 374-379).
} 
a petición del síndico, del fallido o de alguno de los acreedores, declarará cerrado respecto de aquéllos, el procedimiento de verificación (artículo 139 LQ). La declaración de oficio, sólo puede proceder cuando no exista petición del síndico, del fallido o de algún acreedor, dentro de los quince días corridos siguientes a la expiración del plazo señalado ${ }^{41}$. La declaración se notificará por aviso dentro de quinto día (artículo 136 incisos $1^{\circ}$ y $2^{\circ} \mathrm{LQ}$ ).

El procedimiento de verificación explicado anteriormente se denomina verificación ordinaria, por oposición al de verificación extraordinaria. La diferencia entre ambos radica en que en el primero los acreedores concurren a verificar sus créditos y alegar sus preferencias dentro del término de emplazamiento que para dicho efecto contemplan los artículos $52 \mathrm{~N}^{\circ} 6$ y $\mathrm{N}^{\circ} 7$, y $131 \mathrm{LQ}$. En caso contrario, la verificación adquiere el carácter de extraordinaria, la que formalmente no difiere de la ordinaria, por lo que las exigencias señaladas en el artículo 133 LQ son igualmente aplicables a aquélla. Las diferencias dicen relación con la eficacia de la verificación, ya que en la extraordinaria se genera una escasa probabilidad de recuperación del crédito, toda vez que el acreedor solamente será considerado para futuros repartos de fondos (artículo 140 LQ). El solicitante también deberá soportar los costos que supone su verificación. En este sentido, su solicitud debe ser notificada al síndico por cédula, y al fallido y a los acreedores por aviso. Dentro de los quince días siguientes a esta última notificación, deberán deducirse las correspondientes impugnaciones (artículo 140 inciso $\left.2^{\circ} \mathrm{LQ}\right)$.

Aparte de la clasificación efectuada anteriormente entre verificación ordinaria y extraordinaria, es posible realizar otra categorización de las reclamaciones que los acreedores realizan con la finalidad de perseguir el pago de sus créditos en el procedimiento de quiebra. Al respecto, cabe indicar que existe, por una parte, una verificación judicial, que a su vez se distingue entre verificación judicial normal y verificación judicial condicional; y, por otra, una verificación administrativa.

La verificación judicial normal corresponde tanto a la verificación ordinaria como a la extraordinaria, señaladas precedentemente, y se caracteriza por la existencia -al momento de la verificación- de los títulos justificativos de los créditos y preferencias. Por su parte, la verificación judicial condicional es aquella establecida en el artículo 148 inciso 10 LQ. Según lo establecido en esta disposición, ciertos titulares de créditos labores que gocen de determinadas preferencias consagradas en el artículo 2472 del Código Civil, que no tengan un

\footnotetext{
${ }^{41}$ Puga Vial sostiene que la declaración de oficio por el juzgador, reunidos los requisitos que la norma señala, constituye una verdadera obligación legal para el juez, ya que solamente tendría sentido si se la interpreta como un deber y no como una mera facultad del juzgador (PUGA VIAL, Derecho Concursal, cit. nota n. 9, pp. 370-371).
} 
título que haga exigible dichos montos (ya sea porque no existe una sentencia firme y ejecutoriada que obligue a su pago, o bien porque no existe un acuerdo con su empleador anterior a la declaración de quiebra que constituya un título justificativo de su crédito laboral), podrán verificar condicionalmente, ya sea: (a) Con la presentación de la demanda interpuesta con anterioridad a la quiebra, o (b) Con la notificación al síndico de la demanda interpuesta con posterioridad a la declaración de quiebra ante el tribunal competente. Se trata de una verificación sujeta a una condición suspensiva, que en este caso se traduce en que se declare por sentencia firme y ejecutoriada la pretensión invocada ${ }^{42}$.

En el caso de la verificación judicial condicional, el síndico deberá reservar fondos suficientes para el evento de que se acoja la demanda respectiva. Por lo mismo, existe una excepción a la regla general de reparto de fondos contenida en los artículos 147 y 148 inciso $1^{\circ}$ LQ, según la cual los acreedores serán pagados en la forma y orden de preferencia establecida por las leyes, tan pronto como haya fondos para ello.

Tanto en el caso de la verificación judicial normal como en el de la condicional, el acreedor debe cumplir con la petición formal de verificación ante el tribunal de la quiebra. Por lo mismo, el órgano de la quiebra que interviene a fin de dar curso a la verificación es el propio tribunal.

Por su parte, las verificaciones administrativas son aquellas en que no existe solicitud de reclamación de créditos en sede judicial, sino que el escrito de verificación es presentado directamente por el acreedor ante el síndico. Por ello, no es necesario cumplir con las exigencias de comparecencia en juicio, establecidas en la ley $\mathrm{N}^{\circ} 18.120^{43}$.

Dado que las verificaciones administrativas no se sujetan al procedimiento normal de distribución del activo, que supone la elaboración de nóminas de acreedores con los montos de sus créditos y sus preferencias, el artículo 148

\footnotetext{
${ }^{22}$ Gómez Balmaceda, Rafael, y Eyzaguirre Smart, Gonzalo, El derecho de quiebras, $2^{\mathrm{a}}$ ed. aum., Tomo II, Editorial Jurídica de Chile, Santiago, 2011, pp. 382-383.

${ }^{43}$ Existen tres créditos, todos de origen laboral, que se tramitan de acuerdo al procedimiento de verificación administrativa, a saber: a) Los créditos a que se refieren los números 1 (las costas judiciales que se causen en el interés general de los acreedores), y 4 (los gastos que se incurran para poner a disposición de la masa de bienes del fallido, los gastos de administración de la quiebra, de realización del activo y los préstamos contratados por el síndico para los efectos mencionados) del artículo 2472 del Código Civil (artículo 148 inciso $2^{\circ}$ LQ); b) Las remuneraciones de los trabajadores y las asignaciones familiares (artículo $2472 \mathrm{~N}^{\circ} 5$ del Código Civil) se pagarán con cargo a los primeros fondos del fallido, siempre que existan antecedentes documentarios que los justifiquen y aun antes de su verificación (artículo 148 inciso $4^{\circ} \mathrm{LQ}$ ), y c) En los mismo términos recién señalados, se pagarán los créditos por las indemnizaciones convencionales de origen laboral hasta el límite de un equivalente de un mes de remuneración por cada año de servicio y fracción superior a seis meses, y por las indemnizaciones legales del mismo origen que sean consecuencia de la aplicación de las causales señaladas en el artículo $3^{\circ}$ de la ley $\mathrm{N}^{\circ} 19.010$.
} 
inciso $7^{\circ} \mathrm{LQ}$ establece que el síndico deberá cuidar que el monto del saldo del activo sea suficiente para asegurar el pago de los créditos de mejor derecho.

Ahora bien, como se ha señalado anteriormente, la verificación tiene importancia para dos fines:

a) Participación con derecho a voto en las juntas de acreedores, y

b) Participación en las distribuciones que realice el síndico.

Con respecto a lo primero, el artículo $102 \mathrm{LQ}^{44}$ señala cuáles son los acreedores que tendrán derecho a voto en las juntas de acreedores ${ }^{45}$.

Es importante resaltar que un acreedor cuyo crédito se encuentre impugnado de todos modos puede ser admitido a votar, a diferencia de lo que ocurría en la legislación anterior, en donde los créditos impugnados no podían votar. La conclusión anterior se desprende del tenor literal del artículo 102 inciso $2^{\circ}$ $L Q$, que señala que el tribunal, sobre la base de los antecedentes disponibles, determinará cuales créditos no reconocidos, estén o no impugnados, y por qué monto tendrán derecho a votar en la junta de que se trate.

El derecho a voto de los acreedores no reconocidos se limita sólo a la junta en que sean admitidos especialmente a votar, por lo que cada vez que se celebre una junta deberá llevarse a cabo la audiencia señalada. Ahora bien, el derecho a voto de los acreedores no reconocidos, no producirá ninguna consecuencia con respecto a las posibilidades de impugnación que corresponden al síndico y a los acreedores en virtud de lo dispuesto en el artículo 131 y siguientes LQ. Luego, en nada afectará las atribuciones del juzgador para resolver sobre las referidas impugnaciones.

En cuanto a la participación de los acreedores en las distribuciones de fondos que realice el síndico, corresponde aplicar el artículo 143 LQ, según el cual

\footnotetext{
${ }^{44}$ Dice la citada disposición que sólo tendrán derecho a votar en las juntas de acreedores que celebren durante el juicio de quiebra, en primer lugar, los acreedores cuyos créditos estén reconocidos. Esto es, aquellos acreedores cuyos créditos no hayan sido objeto de demanda de impugnación y que además no hayan sido objeto de reserva de impugnación por el síndico, en conformidad al artículo 138 inciso $1^{\circ}$ LQ. También tendrán este carácter aquellos acreedores cuyos créditos hayan sido objeto de reserva de impugnación por el síndico y éste no hubiere deducido la impugnación. Por último, tendrán el carácter de créditos reconocidos aquellos respecto de los cuales se hubiere deducido demanda de impugnación, ya sea en el período ordinario de impugnación o bien como consecuencia de la reserva de impugnaciones, que posteriormente fue rechazada por sentencia firme y ejecutoriada. En segundo lugar, también tendrán derecho a voto en las juntas aquellos acreedores cuyos créditos no se encuentren reconocidos y a los cuales el juez de la quiebra les reconozca el derecho a votar. En efecto, en el día hábil, que no sea sábado, inmediatamente anterior al señalado para la celebración de la junta respectiva, se efectuará una audiencia verbal ante el juez de la quiebra, en la cual el síndico le informará por escrito acerca de la verosimilitud de la existencia y monto de los créditos que todavía no se encuentren reconocidos, pero que hayan sido verificados a más tardar al segundo día hábil, que no sea el sábado anterior a la fecha que corresponda a la celebración de la respectiva audiencia.
}

${ }^{45}$ LiRa Silva, Diego, y Román Rodríguez, Juan Pablo, Reforma al Derecho de Quiebras. Nuevo Estatuto de los Síndicos, Editorial LexisNexis, Santiago, 2006, pp. 88-91. 
participarán en las distribuciones los acreedores cuyos créditos se encuentren reconocidos. Dichos créditos deberán ser incluidos en una nómina que elaborará el síndico, con anotación de las preferencias que les correspondan, y de lo que se les deba por capital e intereses. Dicha nómina se agregará a los autos y se notificará por medio de aviso, que la contendrá íntegramente.

La mencionada nómina deberá ser completada, cumpliendo las mismas formalidades, con los créditos que se reconozcan posteriormente y con aqueIlos que se hubieren omitido por error. Sólo los acreedores que figuren en las nóminas anteriores, podrán participar en las distribuciones que haga el síndico (artículo 143 LQ).

\subsection{Deficiencias del procedimiento de verificación de créditos}

Como se ha podido apreciar en el acápite anterior, en el proceso de verificación intervienen fundamentalmente dos órganos de la quiebra, a saber: el tribunal de la quiebra y el síndico. La función del primero consiste en recibir las peticiones de verificación, remitir copia de ellas al síndico, declarar cerrado el proceso de verificación y, por último, tramitar y resolver las impugnaciones de acuerdo a un procedimiento incidental concursal especial. Por su parte, el síndico debe recibir las verificaciones, examinarlas, impugnarlas en su caso, e instar a la resolución de las impugnaciones. Este proceso, adolece de las siguientes deficiencias que generan un aumento de los costos de la quiebra.

a) Es un procedimiento costoso

En efecto, existen al menos tres notificaciones ${ }^{46}$, dos de ellas por aviso (publicación en el Diario Oficial) y un proceso de notificación civil (que puede significar un trámite de búsquedas positivas y una notificación sustitutiva). La primera notificación por aviso, referida a la publicación de la sentencia que declara la quiebra, se justifica plenamente, por su sentido de publicidad general. No puede predicarse lo mismo de la notificación de la resolución que declara cerrado el proceso de verificación. En efecto, aunque se podría argumentar acerca de la necesidad de publicidad de un hecho que impide acceder a la verificación ordinaria, ello solamente se justificaría en razón del carácter no fatal del plazo de verificación. Por lo tanto, una modificación de la naturaleza de dicho plazo haría innecesaria la publicidad de dicha resolución vía publicación del aviso en el Diario Oficial. Por su parte, si bien la notificación de la impugnación al acreedor objetado se puede explicar por el hecho de que la impugnación es una verdadera demanda de cuestionamiento a la verificación, ello variaría considerando la alternativa de regulación que consiste en establecer

${ }^{46}$ Eventualmente puede existir una cuarta: la notificación por cédula de la resolución que resuelve una impugnación. 
una verificación administrativa debidamente digitalizada en un portal con acceso remoto. Un sistema como éste, que es el que se propone en este trabajo, tornaría innecesarias las últimas dos notificaciones mencionadas, y quizás la primera también podría ser reemplazada por otra forma de información al público.

b) Es un procedimiento lento.

La lentitud del proceso de verificación se debe fundamentalmente a dos razones concurrentes, a saber:

i. Su tramitación es lenta. En cada etapa del proceso de verificación es posible encontrar los siguientes antecedentes que explican la demora en la prosecución del juicio.

- El Ilamamiento a verificar contempla un plazo de 30 días, sin contar los feriados, por lo que perfectamente podría alcanzar a durar 35 días corridos.

- El plazo para verificar vence cuando se notifica la resolución que declara cerrado el proceso de verificación. Por lo mismo, el plazo real de verificación normalmente excederá de 35 días corridos. En efecto, vencido el plazo establecido en la ley, el tribunal, de oficio o a solicitud de alguna de las partes legitimadas, puede o debe, respectivamente, declarar cerrado el procedimiento de verificación. Si transcurren 15 días desde que ha vencido el plazo de llamamiento sin que se haya efectuado tal solicitud, el tribunal deberá declararlo cerrado de oficio. Esta regulación, como se verá más adelante (b) ii.), no se justifica, ya que una mejor alternativa, que tendería a reducir en mayor medida los costos de tramitación, es simplemente regular el vencimiento del periodo de verificación estableciendo la fatalidad del plazo.

- La resolución que declara cerrado el proceso de verificación debe notificarse por aviso, lo que supone un costo adicional y añade algunos días a la duración del procedimiento.

- Se contempla una serie de trámites que aumentan los espacios de tiempo de inactividad del ejercicio jurisdiccional, en razón de ser excesivos, o bien, por no justificarse debidamente. Así, por ejemplo:

- El plazo para impugnar es de 15 días hábiles y se cuenta desde la notificación de la resolución que da por cerrado el proceso de verificación. Este plazo resulta excesivo cuando se considera que las verificaciones, en su gran mayoría, no suelen presentarse al final del periodo de verificación, por lo que el plazo para analizar las verificaciones es en realidad mayor.

- La demanda de impugnación debe ser proveída y, además, debe ser notificada de acuerdo a las normas del Código de Procedimiento Civil, lo cual significa que podrán verificarse dos trámites por el receptor en caso que no exista notificación propiamente personal, a saber: la certificación de búsquedas y la notificación sustitutiva. En dicho supuesto, el receptor 
debe retirar el expediente del tribunal, realizar las búsquedas en dos días distintos y luego devolver el expediente. El impugnante debe presentar un escrito solicitando la notificación por el artículo 44 del Código de Procedimiento Civil. Esta solicitud debe ser proveída, y una vez cumplidos estos trámites, puede retirarse para efectuar la notificación sustitutiva. Un sistema alternativo de publicidad de las verificaciones -como el propuesto en este trabajo- debería modificar los plazos y la tramitación de la notificación de la impugnación, con miras a generar un sistema más rápido y menos costoso.

- El acreedor cuya verificación haya sido objetada posee un plazo de 6 días, luego de notificado, para evacuar su traslado respecto de la impugnación. Este plazo es excesivo si se considera que el plazo normal para toda clase de incidentes es de 3 días. Este último es un término suficiente teniendo en cuenta que la verificación va acompañada de una serie de antecedentes que determinan una verosimilitud calificada de los créditos, por lo que la defensa de su existencia y de la preferencia alegada debería basarse en antecedentes ya aportados al proceso.

- La tramitación posterior a la presentación de la impugnación está sujeta a las normas de los incidentes concursales, que a su vez se remiten a las disposiciones sobre incidentes establecidas en el Código de Procedimiento Civil. Según éstas, el periodo de prueba tiene una duración de 8 días, pudiendo ampliarse a 30 días vía periodo extraordinario de prueba especial (artículo 90 inciso $3^{\circ}$ del Código de Procedimiento Civil). Si bien resulta evidente que debe existir la posibilidad de prueba, debiera suprimirse el término extraordinario. En efecto, la vís atractiva de la quiebra y la verosimilitud de que está premunida la verificación, determinan una prueba que no debiera exceder de la territorialidad del tribunal de la quiebra, máxime si el periodo de prueba existe para efectos de efectuar las peticiones tendientes a acreditar los presupuestos de la verificación o de la impugnación, y no necesariamente a rendir en forma cabal dicha prueba (v. gr. prueba pericial, entorpecimientos, etc. $)^{47}$.

ii. Existencia de plazos no fatales. En efecto, como hemos detallado supra, uno de los plazos más extensos del proceso de verificación es el de llamamiento a los acreedores a verificar. Sin embargo, este término no vence ni produce efectos de preclusión al cumplirse los 30 días siguientes a la notificación de

\footnotetext{
${ }^{47}$ No debe olvidarse que, según la doctrina nacional, se considera que la impugnación a una verificación da origen a un juicio principal. Esto conlleva que en la práctica se altere la tramitación de un incidente normal, aumentando los costos terciarios de administración de justicia, al establecer, por ejemplo, que una resolución que resuelve un incidente se notifique por cédula en vez de notificarse por el estado diario.
} 
la sentencia que declara la quiebra, sino que se extiende hasta que se notifica por aviso en el Diario Oficial la resolución que declara cerrado el proceso de verificación ${ }^{48}$.

Adicionalmente, se consagra un plazo de 15 días siguientes al vencimiento del plazo de llamamiento, donde el juez no puede de oficio declarar cerrado el proceso de verificación ordinaria.

Por otro lado, la resolución que declara cerrado el procedimiento de verificación solamente podrá ser publicada una vez que quede firme y ejecutoriada, por lo que una vez dictada tendrán que transcurrir cinco días hábiles para que proceda la certificación correspondiente.

La solución pasa directamente por establecer la fatalidad del plazo de verificación (aplicación del artículo 78 del Código de Procedimiento Civil), contado desde la fecha de la sentencia que declara la quiebra, lo que no vulnera derecho alguno, porque siempre genera mayor seguridad consagrar términos claros y fatales. Lo importante es que todos los trámites descritos anteriormente generan dos efectos indeseados:

- Se extienden innecesariamente los plazos de verificación, de forma injustificada, tanto desde el punto de vista económico como desde el punto de vista procesal. En efecto, desde la reforma de la ley $N^{0} 18.705$, de 24 de mayo de 1988, esto es, desde hace más de 23 años, se consagró en el Código de Procedimiento Civil, como regla general, la fatalidad de los plazos. De esta manera, vencido el término de días fijado por la ley, operan las consecuencias jurídico-procesales correspondientes, que en este caso consistirían en la preclusión de la posibilidad de verificar el crédito.

- Adicionalmente, se ocasiona una merma en la transparencia, porque el día en que culmina el plazo de verificación se torna más incierto. Ello no ocurriría en caso de contabilizar un determinado plazo a partir del hecho cierto de la publicación de la sentencia que declara la quiebra. Actualmente. se genera litigación periférica y costos terciarios injustificados.

c) Existe una regulación normativa deficiente.

Ésta no contempla una asignación óptima de funciones en lo que respecta a las tareas encomendadas por la ley a los dos órganos que intervienen con mayor intensidad en la verificación (el tribunal de la quiebra y el síndico). En efecto, ante el tribunal de la quiebra se tramitan las verificaciones y se resuel-

\footnotetext{
${ }^{48}$ Sobre la no fatalidad de los plazos de verificación ordinaria, Ver: Puelma Accorsı, Álvaro, Curso de Derecho de Quiebras, 4 a ed. actualizada, Editorial Jurídica de Chile, Santiago, 1985, p. 163; KARzulovic Dawson, Neva, Manual Práctico. Procedimiento sobre quiebras, Editorial Jurídica ConoSur, Santiago, 1985, p. 58; SANDOVAl López, Ricardo, Derecho comercial, Volumen 4, 6 a ed. actualizada, Editorial Jurídica de Chile, Santiago, 2006, pp. 135-137; Gómez Balmaceda y Eyzaguirre Smart, El derecho, cit. nota n. 40, p. 386.
} 
ven sus impugnaciones. Por otro lado, al síndico, dado su carácter técnico y especializado en quiebras, le compete, como función legal, analizar los antecedentes para efectos de determinar si la verificación corresponde a una reclamación legítima y ajustada, pudiendo objetar el crédito por medio de una impugnación, idéntica a la que pueden promover el resto de los acreedores.

Ahora bien, desde el punto de vista de la asignación óptima de funciones, quien puede internalizar de mejor manera los costos de decisión de un conflicto relacionado con una verificación, reduciendo asimismo los márgenes de error, es precisamente el síndico y no el tribunal ${ }^{49}$. Y ello por una variedad de razones:

i. Se trata de un órgano especializado. Ello se ha fortalecido con la dictación de la ley $\mathrm{N}^{\circ} 20.004$, que modificó el artículo 16 LQ, consagrando requisitos de admisibilidad y postulación para poder ser síndico, dentro de los que se encuentran la posesión de determinados títulos profesionales, además de la rendición satisfactoria de un examen de conocimientos. Por contrapartida, el juez de la quiebra, es un juez con competencia civil, que en algunos supuestos tiene competencia común (familia, penal y laboral), y que no goza de ninguna especialización en temas concursales, ni siquiera de perfeccionamiento. La posibilidad de aumentar la probabilidad de error y del costo de decisión, es mayor en un sistema como el actualmente existente.

ii. Una reasignación de funciones no sería extraña a nuestro sistema. En efecto, la posibilidad de que el proceso de verificación sea llevado a cabo ante el síndico de la quiebra encuentra reconocimiento legal en lo referente a la verificación administrativa (artículo 148 LQ). En ésta, basta una presentación informal y sin patrocinio de abogado a efectos de alterar la distribución normal del producto de la liquidación y con la tramitación normal de la verificación. Lo trascedente es que esta verificación administrativa opera en supuestos de mayor entidad y relevancia, ya que se trata de créditos preferentes (y, por tanto, no regidos por el principio de la par condictio creditorum), y que la publicidad es menor, ya que no se requiere efectuar una presentación ante el tribunal de la quiebra, reduciendo o limitando de esta forma las posibilidades de impugnación. La duda, entonces, es: ¿Por qué no ampliar y extender la verificación administrativa al resto del sistema? La respuesta debe ser, desde la eficiencia, instaurar un sistema de verificación administrativa tramitada ante el síndico con el apoyo de un sistema de seguimiento de causas público y totalmente digitalizado, estableciendo plazos fatales y un mecanismo de

\footnotetext{
${ }^{49}$ Sobre el concepto y función de la jurisdicción ver: MARINONI, Luiz Guilherme; Pérez RAGONE, Álvaro y NúÑez OjedA, Raúl, Fundamentos del proceso civil. Hacia una teoría de la adjudicación, Abeledo Perrot/Legalpublishing, Santiago, 2010, pp. 90 y ss.
} 
notificación por el estado diario. Este nuevo sistema propuesto se delineará con mayor detalle más adelante.

\section{La realización de activos}

\subsection{Explicación de la realización de activos}

La realización de los bienes del fallido supone la ejecución por parte de los órganos de la quiebra (fundamentalmente el síndico y la junta de acreedores) de sus deberes y facultades en relación con la disposición de los bienes desasidos. De acuerdo a nuestra normativa sobre quiebras, los plazos de realización del activo son los siguientes:

a) Seis meses, en el caso de la realización sumaria del activo. El artículo 109 LQ trata de la realización sumaria del activo, en aquellos casos en que de la cuenta del síndico apareciere que el producto probable de la realización del activo de la quiebra no excederá de mil unidades de fomento. A dicha estimación del valor del activo se podrán oponer el fallido o cualquiera de los acreedores, debiendo manifestarlo en la junta en que se da a conocer la cuenta presentada por el síndico. Dicha oposición será la única que se puede presentar en esta materia (artículo 109 inciso $1^{\circ}$ y $2^{\circ} \mathrm{LQ}$ ).

b) Seis meses contados desde la primera junta de acreedores, tratándose de bienes muebles, y nueve meses tratándose de bienes inmuebles. Ambos plazos pueden ser prorrogados por el tribunal por una sola vez, por un máximo de seis meses, siempre que el síndico lo solicite con al menos quince días de anticipación a su vencimiento. Estos plazos se aplican en los demás casos de realización de los bienes del activo del fallido (artículo 130 LQ).

Para efectos de entender de mejor forma la dinámica del funcionamiento de los plazos involucrados en el procedimiento de realización, cabe resaltar que, como se ha indicado, el plazo de liquidación es de seis o nueve meses contados desde la primera junta de acreedores. Pues bien, la ley establece que la primera junta se llevará a cabo en un plazo que no sea inferior a 30 ni superior a 40 días hábiles ${ }^{50}$, contados desde la publicación de la sentencia que declara la quiebra (artículo 106 LQ) que, como es sabido, la dicta el tribunal luego de un proceso de cognición breve (artículos 39 a 52 LQ). Por lo mismo, el plazo de seis y el de nueve meses se incrementan a lo menos en un mes y medio adicional. Si además se considera que toda la etapa previa a la declaración de la quiebra puede durar dos meses adicionales, resulta que la realización no ocurrirá antes de cumplirse un año de la presentación

${ }^{50}$ De conformidad al artículo $5^{\circ}$ inciso $3^{\circ} \mathrm{LQ}$, los términos de días se suspenden durante los días feriados. 
de la solicitud de falencia. Por otro lado, no existen incentivos para acelerar la realización, toda vez que no se estipula sanción especial para el caso de inobservancia de los plazos mencionados ${ }^{51}$.

Con todo, el síndico deberá presentar en la primera reunión ordinaria un informe completo, un programa de realización del activo, un plan de pago del pasivo, y una estimación de los gastos de administración de la quiebra (artículo 111 LQ). En cumplimiento de lo anterior, el síndico deberá ajustarse a las instrucciones generales que al efecto haya dictado la Superintendencia de Quiebras. Ello determina que el síndico, a la fecha de la primera junta ordinaria (es decir, aproximadamente un mes después de la primera junta de acreedores, y dos meses y medio después de la sentencia que declara la quiebra), debe presentar un programa de realización de activo. Lo problemático es que este plan de liquidación podría perfectamente presentarse en la primera junta de acreedores, toda vez que el síndico ya habrá completado a lo menos un mes y medio en el ejercicio de su cargo, lo que justifica presumir que ya poseerá entonces un conocimiento acabado acerca del programa que pretende aplicar al procedimiento concursal. Esto guardaría armonía con lo establecido por el artículo 130 LQ, en cuanto a que el plazo de realización debe contarse desde la primera junta, lo cual implica que en dicho momento el síndico tendría pleno conocimiento del curso a seguir, máxime tratándose de un órgano administrativo, con respecto al cual ha existido una especial preocupación por su profesionalización en la legislación.

Ahora bien, los artículos 109, 120, 121 y 122 LQ, establecen las distintas formas de realización de los bienes de la masa y de las dos modalidades que dicha realización debe tener (las que han sido señaladas anteriormente). Sin embargo, la junta de acreedores, con el voto favorable de más de la mitad del pasivo de la quiebra con derecho a voto, podrá acordar en cualquier tiempo una forma distinta de realización, como asimismo modalidades distintas para realizar los bienes de la masa ${ }^{52}$.

Ahora bien, la junta puede acordar, como forma de realización de los bienes, la subasta pública al mejor postor, situación en la cual no necesitará del

\footnotetext{
${ }^{51}$ Puelma Accorsi, Curso, cit. nota n. 46, p. 174. En este mismo sentido, Juan Esteban Puga Vial señala, a propósito de los plazos de realización del activo, que: "Esta norma no pasa de ser un sueño del legislador, porque no está complementada con sanciones claras y precisas que la hagan efectiva" (PugA VIAL, Derecho Concursal, cit. nota n. 9, p. 647).

${ }^{52}$ El síndico es el único órgano legitimado para oponerse a la modificación del sistema legal de realización de los bienes de la masa, por medio de un escrito fundado cuya presentación da origen a un incidente que debe ser resuelto por el juez dentro de tercero día. La apelación a la resolución del juez se concederá en el sólo efecto devolutivo, y gozará de preferencia para su agregación extraordinaria a la tabla y para su fallo (artículo 123 incisos $1^{\circ}$ y $3^{\circ}$ y artículo $5^{\circ}$ LQ).
} 
acuerdo del fallido, por cuanto se trata de una forma de realización que otorga las garantías suficientes de transparencia y publicidad. Esta forma de realización de los bienes, por medio de pública subasta, sólo es aplicable a las especies corporales muebles y a los créditos activos. En efecto, el inciso $3^{\circ}$ del artículo 122 LQ hace aplicable dicho procedimiento, de acuerdo a las normas del juicio ejecutivo, "a todas las otras especies de bienes corporales o incorporables". Se exceptúan los bienes señalados precedentemente, como también aquellos expuestos a próximo deterioro ${ }^{53} \mathrm{o}$ a una desvalorización inminente ${ }^{54}$, y aqueIlos que exijan una conservación dispendiosa ${ }^{55}$. Respecto de estos últimos, por motivos de celeridad en su realización, no resultaría útil liquidarlos por medio de una subasta pública. En caso de que la junta adopte este acuerdo, la subasta se efectuará ante el juez de la quiebra (inciso $2^{\circ}$ del artículo 123 LQ).

Dos modalidades de destinación de activo no suponen realización, a saber: la venta o enajenación como unidad económica ${ }^{56}$ y la continuación efectiva del giro ${ }^{57}$. Ambos casos quedan al margen de la presente investigación, porque

\footnotetext{
${ }^{53}$ Según el artículo 23 letra A del Instructivo de la Superintendencia № 5, se entiende por bienes expuestos a un próximo deterioro aquellos con fecha de vencimiento próximo o cuyo consumo o uso debe realizarse en un breve período de tiempo.

${ }^{54}$ Según el artículo 23 letra B del Instructivo de la Superintendencia $N^{\circ}$ 5, se entiende por bienes expuestos a una desvalorización inminente, aquellos que de no ser enajenados antes de la primera junta de acreedores, con posterioridad a ella tendrán un valor muy inferior al que se obtendría al enajenarlos antes de dicha junta, como los juguetes que se deben vender antes de navidad o como la ropa de temporada.

${ }^{55}$ Según el artículo 23 letra C del Instructivo de la Superintendencia № 5, se entiende por conservación dispendiosa, cuando el valor necesario para asegurar la integridad de los bienes, hasta la primera junta de acreedores, sea superior o igual al $50 \%$ de su valor comercial, situación que deberá estar debidamente documentada.

${ }^{56}$ El artículo 124 LQ establece que los acreedores que reúnan más de la mitad del total pasivo de la quiebra, podrán acordar la enajenación de todo o parte del activo de la misma como un conjunto o unidad económica, en subasta pública y al mejor postor. El instituto de la enajenación como unidad económica se estableció para mantener unificado el activo de la quiebra, buscando impedir un modelo liquidatorio. Se pretende consagrar un instrumento de pervivencia del conjunto patrimonial del deudor, reasignando los recursos de titulares insolventes en quienes consideren que con un cambio de estructura y gestión pueden hacer viables conjuntos de activos hasta la fecha en peligro de desintegración. Al respecto, consultar: VARAS LIRA, Felipe, "La enajenación como unidad económica en el derecho concursal chileno", en Juan Pablo Román Rodríguez (coord.), Salvamento de las empresas en crisis, Editorial Jurídica de Chile, Santiago, 2001, p. 327; y Carrasco Delgado, Nicolás, "Hipoteca Legal en la legislación chilena de quiebras, a propósito de la enajenación como unidad económica", en Mauricio Tapia Rodríguez [et al.], Estudios sobre garantías reales y personales, Libro Homenaje al Profesor Manuel Somarriva Undurraga, Vol. I, Editorial Jurídica de Chile, Santiago, 2008, pp. 403-426.
}

${ }^{57} \mathrm{Al}$ síndico le corresponde continuar efectivamente el giro del fallido, ya sea con la autorización del tribunal de la quiebra o bien con acuerdo adoptado en tal sentido por la junta de acreedores. Esto es, la junta de acreedores tiene la facultad en virtud del artículo 27 № 9 y artículo 112, ambos de la ley № 18.175, para acordar pagarse de sus créditos con los resultados de la explotación de la empresa 
de adoptarse dichas modalidades, se reducen o eliminan los problemas generados por la lentitud e ineficiencias del procedimiento de quiebras que se han analizado, en cuanto no se vinculan con una liquidación del activo diseminada. Es importante indicar que, temporalmente, la continuación efectiva del giro suspende el procedimiento liquidatorio normal (artículo 130 inciso $2^{\circ}$ LQ).

\subsection{Deficiencias de la legislación nacional sobre realización de activos}

Como se ha señalado, la verificación y la realización del activo son trámites interdependientes. Así, no es posible obtener una solución satisfactoria, en términos de bienestar desde el análisis económico del Derecho procesal, sino se regulan ambos extremos con una misma finalidad. En otras palabras, agilizar la tramitación de la verificación no conducirá a ningún destino, si no ocurre lo propio con la realización del activo, y viceversa. Ello, porque aun estando reconocidos debidamente los acreedores que deben concurrir al pago de sus créditos y sus preferencias, el proceso de quiebras no avanzará si todavía no se liquida el activo comprometido en el estado de falencia. Por su parte, si dicha liquidación ha llegado a su fin, y los fondos se encuentran disponibles para su distribución, ésta no ocurrirá mientras no se tenga certeza sobre a quiénes corresponde asignarlos y con qué orden de prioridad.

Habiendo hecho esta constatación, debe señalarse que las deficiencias a este respecto se han detectado desde el punto de vista de los plazos que involucra la actividad de realización del activo, en dos de sus extremos, a saber:

a) Inicio del cómputo del plazo de realización.

Ya hemos señalado que los plazos normales de realización del activo son de seis meses para los bienes muebles, y de nueve meses para los bienes inmuebles, con la posibilidad de ampliarlos por una sola vez por seis meses adicionales. Dichos plazos se cuentan desde la celebración de la primera junta de acreedores, que tiene lugar en un plazo no menor a 30 días y no mayor a 40. Por lo tanto,

en falencia, y no con el resultado del proceso de liquidación normal de la quiebra. Esta intervención de la junta de acreedores viene a representar el poder de disposición que ejerce sobre los bienes desasidos del fallido, toda vez que el síndico de quiebra deberá dar cumplimiento al acuerdo de la junta de acreedores que decida la continuación efectiva del giro, no pudiendo oponer objeción alguna. Se constituye de esta forma un poder de dirección de la conducta de los síndicos. El plazo inicial de la continuación efectiva del giro, total o parcial, podrá ser prorrogado por una sola vez, hasta por un año. Para que eso ocurra debe adoptarse un acuerdo por una junta extraordinaria de acreedores, con la mayoría necesaria para adoptar el acuerdo de continuar efectivamente el giro del fallido, es decir, con el acuerdo de al menos dos tercios del pasivo de la quiebra con derecho a voto. Es importante señalar que el plazo original de la continuación efectiva del giro del fallido podrá ser prorrogado hasta por un año, por lo que puede ser una prórroga menor a un año pero no superior a dicho período. Cuando se decide prorrogar el plazo original de la continuación efectiva del giro del fallido, la administración deberá recaer por el plazo prorrogado en una persona distinta del síndico. 
existe un periodo de aproximadamente un mes y medio de gestión del síndico, en que no se llevan a cabo actividades de liquidación alguna, haciendo presente que el síndico, de conformidad con la normativa legal y con los instructivos dictados por la Superintendencia de Quiebras, debe asumir el cargo tan pronto como el Secretario del tribunal de la quiebra le comunique su designación ${ }^{58}$, procediendo a continuación y de forma inmediata (artículo 94 de la LQ), a llevar a cabo los trámites de determinación del activo (incautación y realización de inventario). La urgencia de llevar a cabo esta determinación no guarda relación con el aplazamiento del plazo de inicio del cómputo de realización. Asimismo, existe una inconsistencia orgánica no menor, toda vez que el síndico deberá presentar en la primera junta ordinaria de acreedores un informe completo, un programa de realización del activo, un plan de pago del pasivo, y una estimación de los gastos de administración de la quiebra (artículo 111 LQ). Dicha junta se celebra habitualmente en el mes siguiente a la realización de la primera junta de acreedores, por lo que habrán pasado aproximadamente dos meses y medio desde la fecha en que el síndico asumió su cargo y determinó el activo, sin que exista claridad acerca del programa de realización del activo. Al respecto, se hace urgente que dicho programa sea presentado en la primera junta de acreedores, ya que desde dicho momento se cuenta el plazo de realización. No se justifica, entonces, que el plazo de liquidación comience a contarse cuando todavía no exista un plan al cual deba sujetarse, lo que aumenta la probabilidad de que no se ejecuten actos de realización en dicho periodo intermedio, por el riesgo de que aqueIlos realizados acaben siendo inconsistentes con los objetivos planteados en la planificación respectiva. Además, cabe argumentar que, si la determinación del patrimonio concursado opera con criterios de urgencia, no se justifica que el síndico cuente con más de dos meses para formular su plan de prosecución de la quiebra. Podría objetarse a esta crítica que la regulación no contempla una solución como la aquí planteada, debido a que el síndico provisional podría no ser ratificado en su cargo en la primera junta de acreedores. Sin embargo, ello no constituye una buena razón, debido a que la probabilidad de revocación es escasa. Por lo demás, si llegase a ocurrir, siempre es preferible que exista un trabajo previo de planificación a que no exista uno, toda vez que dicha labor no constituirá un costo hundido, sino que podrá servir como base de la planificación del

\footnotetext{
${ }^{58}$ En este sentido, el artículo 55 LQ señala que inmediatamente de pronunciada la sentencia que declara la quiebra el secretario del tribunal cuidará que se notifique dicha resolución a la brevedad posible, al síndico provisional, titular y suplente. En este mismo sentido, ver los artículos $1^{\circ}, 4^{\circ}$ y $7^{\circ}$ del Instructivo de la Superintendencia de Quiebras № 4, de fecha 29 de diciembre de 2009, que "instruye sobre aspectos procesales, juntas de acreedores de la Quiebra, audiencia previa a la aplicación de sanciones y cómputo de plazos e interpreta administrativamente la ley y deroga oficios, circulares e instructivos que indica".
} 
nuevo síndico, quien -en la alternativa de lege ferenda que analizamos- debería contar con un plazo debidamente acotado y fatal para cumplir con el encargo de formular su plan de realización ${ }^{59}$. Resulta evidente que la celebración de la primera junta de acreedores debe tener lugar dentro de márgenes de tiempo menores que los existentes, lo que incentivará una más rápida verificación, ya que los acreedores tendrán incentivos para participar con derecho a voto en la misma. Incluso existen quienes consideran que el procedimiento de realización solamente se inicia cuando la sentencia que declara la quiebra se encuentra firme y ejecutoriada ${ }^{60}$. Ello significaría que, en el supuesto de haberse deducido recurso de reposición, la sentencia confirmatoria de la sentencia que declara la quiebra puede ser bastante posterior a la fecha la primera junta de acreedores o bien de la primera junta ordinaria de acreedores. Sin embargo, dicha opinión debería ser desestimada, porque la única posibilidad legal de suspender la realización de activos, habiéndose deducido recurso de reposición, es que se acoja una orden de no innovar (artículo 57 inciso $4^{\circ} \mathrm{LQ}$ ), por lo que de no ser así, la realización no se supeditará a la firmeza de la sentencia que abre el concurso.

b) Término del procedimiento de realización

En opinión de la doctrina, los plazos legales de realización son no fatales ${ }^{61}$, de forma que llegado su vencimiento no se generan mayores consecuencias jurídicas relacionadas con la preclusión de la posibilidad de realización, produciéndose simplemente una situación de morosidad del síndico para con los acreedores, que daría a éstos el derecho de constreñirlo a su cumplimiento. Si bien se considera que dicha interpretación se encuentra acorde con el texto legal, ella nada aporta a la búsqueda de una mayor eficiencia del procedimiento, de modo que lo único que logra es reproducir los vicios que ocasiona el carácter no fatal de los plazos.

En la práctica, el procedimiento de realización de bienes se encuentra sujeto a demoras e ineficiencias derivadas de una regulación que carece de uniformidad, de la exigencia de publicaciones costosas (como aquellas efectuadas por el Diario Oficial) y de la posibilidad de promover incidentes. Así ocurre con la reglas de la venta en pública subasta, la que se sujeta a antiguos dictámenes de la hoy extinta Fiscalía Nacional de Quiebras ${ }^{62}$.

\footnotetext{
${ }^{59}$ Obsérvese que la posibilidad de demorar el inicio del cómputo de realización de acuerdo a la propuesta realizada, en caso de revocación, puede constituir un incentivo para no adoptar esta última decisión, ya que los acreedores son los más interesados en la prosecución rápida del proceso de quiebras.

${ }^{60}$ En este sentido: Gómez Balmaceda y Eyzaguirre Smart, El derecho, cit. nota n. 44, pp. 403-404.

${ }^{61}$ Gómez Balmaceda y Eyzaguirre Smart, El derecho, cit. nota n. 44, pp. 419-422.

${ }^{62}$ Para conocer las diferentes etapas e incidentes que pueden plantearse en la tramitación de una subasta pública, ver: Contreras Strauch, Osvaldo, Insolvencia y Quiebra, Editorial Jurídica de Chile, Santiago, 2010, pp. 228-229.
} 
Por otro lado, puede afirmarse que un plazo de realización de bienes muebles e inmuebles, no debiera demorar seis o nueve meses, estimándose que dichos términos deberían ser los plazos máximos, incluida la opción de prórroga, salvo quizás en caso de existencia de bienes ubicados en el extranjero. Para agilizar la liquidación, debería legislarse sobre el reembargo y aclarar normativamente que, en caso de quiebra, la enajenación de bienes inmuebles que poseen sucesivos embargos y gravámenes procederá sin previa autorización del tribunal ante el cual se trabó dicha limitación a la libre circulación (artículo 1464 № 3 y 4 del Código Civil). Bastaría que el tribunal de la quiebra comunique la realización del bien a los tribunales respectivos, a fin de resguardar la debida publicidad y el ejercicio de los derechos de verificación ordinaria o extraordinaria de los acreedores que sean parte en los otros procesos. De esta forma, la realización de los bienes inmuebles se sujetará a los plazos y términos fijados para la ejecución de inmuebles de acuerdo a las reglas del juicio ejecutivo de obligaciones de dar, pudiendo reducirse ciertas formalidades, según se indicará en el acápite $\mathrm{V}$.

\section{Derecho Comparado}

A continuación se desarrollará un análisis comparado del procedimiento de verificación de créditos en diversos países, resaltando los principales aspectos involucrados en esta etapa de verificación.

Las regulaciones consultadas a este respecto son las de los siguientes sistemas concursales: Alemania ${ }^{63}$, Argentina $^{64}$, Australia $^{65}$, Brasi $^{66}{ }^{,}$Canadá $^{67}$, Colombia $^{68}$,

\footnotetext{
${ }^{63}$ Insolvency Statute (Insolvenzordnung). Disponible en http://www.gesetze-im-internet.de/englisch_inso/ index.html (sitio del Ministerio de Justicia Federal de Alemania) [visitado el 20/01/2012].

${ }^{64}$ Ley de Concursos y Quiebras. Disponible en http://www.infoleg.gov.ar/infolegInternet/anexos/2500029999/25379/texact.htm (sitio de Información Legislativa del Ministerio de Economía y Finanzas Públicas) [visitado el 20/01/2012].

${ }^{65}$ Bankruptcy Act 1966. Disponible en http://www.comlaw.gov.au/Details/C2011C00266 (sitio ComLaw del Gobierno de Australia) [visitado el 20/01/2012].

${ }^{66}$ Lei № 11.101, de 9 de fevereiro de 2005, regula a recuperação judicial, a extrajudicial e a falência do empresário e da sociedade empresária. Disponible en: http://www.planalto.gov.br/ccivil_03/_ ato2004-2006/2005/lei/l11101.htm (sitio de la Presidencia de la República) [Consulta el 20 de enero de 2012].

${ }^{67}$ Bankruptcy and Insolvency Act. Disponible en <http://laws-lois.justice.gc.ca/eng/acts/B-3/index.html (sitio del Departamento de Justicia de Canadá) [visitado el 20/01/2012].

${ }^{68}$ Ley 1116 de 2006, por la cual se establece el Régimen de Insolvencia Empresarial en la República de Colombia y se dictan otras disposiciones. Disponible en http://www.secretariasenado.gov.co/senado/basedoc/ley/2006/ley_1116_2006.html (sitio del Senado de la República de Colombia) [visitado el 20/01/2012].
} 
España $^{69}$, Estados Unidos ${ }^{70}$, Finlandia ${ }^{71}$, Hong Kong ${ }^{72}$, Nueva Zelanda ${ }^{73}$, Perú ${ }^{74}$ y Singapur ${ }^{75}$.

\section{Presentación de la solicitud}

En esta primera etapa, es posible agrupar las distintas soluciones empleadas por las legislaciones estudiadas de la forma que se detalla a continuación.

\subsection{Ante quién debe presentarse}

La mayoría de los sistemas estudiados establecen que los acreedores deberán presentar sus créditos a verificación ante el síndico o el administrador designado en el proceso de insolvencia de que se trate. En contraste, sólo contados sistemas prevén que se presente ante el órgano jurisdiccional.

\subsection{Forma de presentación y contenido}

En general, son exigencias comunes las siguientes:

a) Deben presentarse por escrito.

b) Deben señalarse: la individualización del acreedor y del deudor; la cuantía del crédito; la causa y la preferencia invocada ${ }^{76}$.

${ }^{69}$ Ley 22/2003, de 9 de junio, Concursal. Disponible en http://www.boe.es/aeboe/consultas/bases_datos/act.php?id=BOE-A-2003-13813 (sitio de la agencia estatal Boletín Oficial del Estado) [visitado el 20/01/2012].

${ }^{70}$ Bankruptcy Code. Disponible en http://www.law.cornell.edu/uscode/html/uscode11/usc_sup_01_11. html (sitio del Instituto de Información Legal de Cornell University Law School) [visitado el 20/01/2012].

${ }^{71}$ Bankruptcy Act. Disponible en http://www.finlex.fi/en/laki/kaannokset/2004/en20040120.pdf (sitio de base de datos de la legislación del Estado) [visitado el 20/01/2012].

${ }^{72}$ Según información consignada en sitio web del Official Receiver's Office. Disponible en http://www. oro.gov.hk/eng/home/home.htm [visitado el 20/01/2012].

${ }^{73}$ Insolvency Act 2006 Disponible en http://www.legislation.govt.nz/act/public/2006/0055/latest/ DLM385299.html (sitio del Parliamentary Counsel Office) [visitado el 20/01/2012].

${ }^{74}$ Ley General del Sistema Concursal. Disponible en http://www.bvindecopi.gob.pe/legis/l27809.pdf (sitio del Instituto Nacional de Defensa de la Competencia y de la Protección de la Propiedad Intelectual) [visitado el 20/01/2012].

${ }^{75}$ Bankruptcy Act. Disponible en http://statutes.agc.gov.sg/aol/search/display/view.w3p;page=0;query $=$ Docld $\% 3$ Ac342424a-8867-494a-bbab-91b696d12bdc\%20Depth\%3A0;rec=0;resUrl=http\%3A\%2 F\%2Fstatutes.agc.gov.sg\%2Faol\%2 Fbrowse\%2FtitleResults.w3p\%3Bletter\%3DB\%3Btype\%3DactsAll ; whole=yes (sitio del Gobierno de Singapur) [visitado el 20/01/2012].

76 "La comunicación consta de dos piezas: la primera, el escrito de comunicación, donde deberá quedar identificado cada crédito, su titular, así como determinado su importe; y la segunda; el material probatorio necesario que justifica la existencia del crédito. [...] Los elementos esenciales de la comunicación son los precisos para individualizar y concretar el crédito: la identificación del titular, 
c) Debe acompañarse una copia de los documentos que acreditan el crédito reclamado.

En algunos países, se contempla además:

a) El uso de formularios preestablecidos para solicitar la verificación de créditos (v. gr., Australia, Canadá, Estados Unidos, Hong Kong, Nueva Zelanda, Perú y Singapur).

b) La posibilidad de presentar la verificación vía Internet ${ }^{77}\left(v\right.$. gr., Alemania ${ }^{78}$, Hong Kong, Nueva Zelanda y Singapur).

c) El pago de una tarifa o arancel.

\subsection{Plazo}

En todos los casos se establece un plazo dentro del cual los acreedores deberán presentar sus verificaciones. En ciertos sistemas, está fijado por ley; en otros, lo determinará el mismo síndico o administrador. Luego de vencer este período, las verificaciones podrán presentarse extraordinariamente.

Las legislaciones que permiten la presentación extraordinaria de verificaciones de crédito, no utilizan como alternativa el establecimiento de un plazo de verificación extraordinaria. En general, rige la lógica de que las nuevas

el fundamento del crédito y su importe. Cuando falta alguno de estos elementos la comunicación se considera ineficaz y no produce efecto alguno. [...] La indicación del grado de preferencia es esencial sólo a los efectos de asignar al crédito el puesto que le corresponda en la prelación. Su ausencia no hace ineficaz la comunicación, sino que reduce el crédito a la condición de ordinario. En ese caso, la comunicación del crédito produce, en principio, efectos, pero será defectuosa" [las cursivas son de la autora] (Bermejo, Nuria, "Comunicación de créditos" (Art. 85) en Rojo, Ángel y Beltrán, Emilio (dirs.), Comentario de la Ley Concursal, Thomson Civitas, Madrid, 2004, p. 1536).

${ }^{77} \mathrm{Sin}$ duda que lo tradicional es que se remita materialmente toda la documentación original al síndico. Sin embargo, en ciertos países, se ha desarrollado la posibilidad de presentar una verificación electrónicamente, vía e-mail. Respecto de los documentos, se han creado regulaciones legales y se ha desarrollado el debido soporte técnico, con el fin de asegurar la fidelidad de la digitalización de documentos.

La idea fundamental es que se debe contar con una fuente fidedigna de información. Si se opta por no exigir la presentación material de documentos en el tribunal o en la oficina del síndico y se permite su remisión electrónica, deben proporcionarse los medios jurídicos y técnicos que aseguren la fidelidad de los mismos.

En Chile, la nueva justicia de cobranza laboral y previsional implementó un procedimiento (ley № 20.087) que contempla la litigación electrónica en los siguientes términos: "Siempre que alguna de las partes lo solicite para sí, y el tribunal acceda a ello, las actuaciones procesales, a excepción de las audiencias, podrán realizarse por medios electrónicos que permitan su adecuada recepción, registro y control. En este caso el administrador del tribunal deberá dejar constancia escrita de la forma en que se realizó dicha actuación" (art. 433).

${ }^{78}$ La Insolvenzordnung establece que la presentación de las verificaciones de crédito podrá efectuarse mediante el envío de un documento electrónico, si el administrador de la insolvencia ha consentido explícitamente en ello. En tal caso, los documentos justificativos del crédito deberán ser presentados posteriormente sin demora. 
verificaciones no podrán participar de los repartos previos, sino sólo de los futuros (v. gr., Singapur), haciéndose cargo el acreedor de las costas que genere. Algunas legislaciones sujetan la posibilidad de presentar extraordinariamente estas verificaciones a la aprobación del tribunal ( $v$. gr., Estados Unidos), o bien al pago de una suma de dinero ( $v$. gr., Finlandia).

\section{Trámites posteriores a la presentación de la solicitud}

\subsection{Publicidad de las solicitudes}

Las leyes concursales disponen que las solicitudes presentadas, junto con la documentación correspondiente, sean colocadas a disposición de los acreedores para su conocimiento. Para estos efectos, dichos documentos se encontrarán disponibles en las oficinas del síndico o administrador, o en el juzgado, o bien se les efectuará una notificación a los acreedores, a fin de conocer qué créditos se han presentado a verificación. Esto es fundamental para poder deducir posteriormente observaciones o impugnaciones fundadas.

\subsection{Actividad del receptor de la presentación}

A partir de esta fase del procedimiento, si bien varias legislaciones continúan guardando similitudes más o menos estrechas entre sí, cada una de ellas posee particularidades o trámites específicos, cuyo estudio acabado demanda una exposición separada.

a) En legislaciones como las de Australia, Canadá, Hong Kong, Nueva Zelanda y Singapur -las cuales presentan entre sí un esquema general muy similar-, el síndico o administrador procederá de inmediato a examinar cada solicitud presentada junto con sus fundamentos, pues él será el encargado de decidir "en primera instancia" la procedencia de las solicitudes presentadas.

Para acometer dicha tarea, se le otorga la facultad de requerir de los acreedores solicitantes documentación adicional a la originalmente presentada u otras pruebas en apoyo de su reclamación.

Así, y dentro de determinado plazo, el síndico o administrador admitirá o rechazará, total o parcialmente, cada solicitud. En caso de rechazo, total o parcial, deberá además notificar dicha decisión al respectivo acreedor, indicándole los motivos de la misma.

b) De manera similar, en España, la Ley Concursal dispone que corresponderá a la administración concursal determinar la inclusión o exclusión, en la lista de acreedores, de los créditos puestos de manifiesto en el procedimiento. Añade que esta decisión se adoptará respecto de cada uno de los créditos, tanto de los que se hayan comunicado expresamente como de los que resultaren de los libros y documentos del deudor o que por cualquier otra razón constaren en el concurso. 
c) En Alemania, el administrador deberá inscribir, en la lista de acreedores, todo crédito presentado. Luego, depositará esta lista en la secretaría del juzgado para que sea objeto de conocimiento y examen por parte de los interesados. Se observa que, a diferencia de lo que ocurre en los países mencionados en (a) y (b), en esta oportunidad el administrador no cumple la función de decidir la admisión o rechazo de un crédito.

d) En Argentina, el síndico organizará en legajos las solicitudes de verificación y la documentación acompañadas por los acreedores. Asimismo, él goza de facultades de investigación sobre los libros y documentos del concursado, y del acreedor. Esto, pues una vez recibidas las observaciones formuladas por los interesados, deberá entregar al tribunal un informe individual de cada solicitud. Es decir, el síndico no cumple una función decisoria.

e) En Brasil, el administrador, en base a las informaciones y documentos obtenidos, ordenará la publicación de la "relación de acreedores", indicando el lugar y el plazo para que las personas legitimadas para impugnar accedan a los documentos que sirvieron de fundamento a la elaboración de dicha relación. Es decir, el administrador no tiene funciones decisorias ni informativas.

f) En Colombia, en el proceso de reorganización, el deudor deberá elaborar un proyecto de calificación y graduación de créditos, el cual servirá de base para la verificación de créditos. El deudor deberá entregar el proyecto al "promotor", el que a su vez lo presentará al juez ${ }^{79}$ junto con el inventario y avalúos de los activos del deudor.

En el proceso de liquidación judicial, se establece un plazo dentro del cual los acreedores deberán presentar sus créditos al "liquidador", de la misma manera que en la generalidad de los países, como se apuntó más arriba. Luego, el liquidador remitirá al juez toda la documentación presentada, junto con un proyecto de calificación y graduación de créditos.

g) En Finlandia, el administrador verificará la legitimidad de los créditos presentados y de su posible orden de prelación, elaborará una primera una primera versión de la "lista de desembolsos" (que detalla la forma en que los activos de la masa han de ser distribuidos a los acreedores), y la pondrá en conocimiento del deudor y de los acreedores.

h) En Perú, el órgano encargado de recibir las solicitudes es la Secretaría Técnica del INDECOPI. Una vez vencido el plazo de presentación, la Secretaría notificará al deudor para que exponga su opinión sobre las solicitudes, la que en todo caso no es vinculante. Luego, publicará en su local un aviso con la lista de acreedores.

${ }^{79}$ Cabe precisar que en el régimen de insolvencia colombiano, la Superintendencia de Sociedades reviste la calidad de juez. 


\subsection{Interposición de objeciones y decisión final}

a) En Australia, Canadá, Hong Kong, Nueva Zelanda y Singapur, tomada y notificada la decisión del síndico, el deudor y cualquier acreedor podrán solicitar su revisión judicial dentro del plazo correspondiente. De este modo, el tribunal podrá confirmar, revertir o modificar la decisión del síndico, estableciendo definitivamente qué créditos serán reconocidos.

b) En España, adoptada la decisión por parte de la administración concursal, todas las cuestiones que se susciten en materia de reconocimiento de créditos serán tramitadas y resueltas por medio del incidente concursal. Es decir, las controversias que deseen plantear los interesados deberán tramitarse y decidirse por el tribunal, de acuerdo a este procedimiento establecido en la Ley Concursal.

De los sistemas descritos hasta ahora en este apartado, se aprecia que todos se caracterizan en su estructura por la existencia de una primera etapa de decisión, a cargo del síndico o administrador: y, de una segunda etapa de decisión, ya definitiva, en manos del tribunal, la que sólo procede en caso de plantearse controversias respecto del resultado de la primera etapa decisoria. De ahí resulta que las decisiones adoptadas por el síndico o administrador que no sean controvertidas, quedan firmes y no podrán ser objeto de revisión judicial.

c) En Alemania, la asamblea de acreedores celebra una "junta de verificación" (cuya fecha la fija el tribunal) para que, habiendo tenido la oportunidad de examinar los créditos presentados, el administrador, el deudor u otro acreedor, formulen sus impugnaciones. Cada impugnación se debatirá individualmente.

Si un crédito resulta discutido por el administrador o por un acreedor -la oposición del deudor no impide la admisión del crédito-, permanecerá para el acreedor la posibilidad de perseguir la admisión contra los impugnantes. Cuando el crédito impugnado se basa en una escritura pública o en una sentencia firme, la carga de la impugnación recaerá sobre la parte impugnante, mientras que en los demás casos dependerá del acreedor impugnado continuar el procedimiento tendiente a la determinación de su crédito, mediante una demanda de admisión que debe interponerse en el procedimiento ordinario ante el juzgado de primera instancia ante el cual está o estaba pendiente el procedimiento de insolvencia.

De este modo, un crédito valdrá como admitido en la medida en que contra el mismo no haya sido formulada oposición ni por el administrador ni por un acreedor, o que haya sido rechazada la oposición formulada.

d) En Argentina, como ya se anticipó, el deudor y los acreedores deberán concurrir dentro de plazo al domicilio del síndico a efectos de formular las impugnaciones y observaciones que les merezcan las solicitudes presentadas. Vencido el plazo, el síndico deberá redactar un informe sobre cada solicitud de verificación en particular, para ser entregado al juez. 
Dentro de los diez días de presentado el informe por parte del síndico, el juez decidirá sobre la procedencia y alcances de las solicitudes formuladas por los acreedores. Cuando existan observaciones, el juez decidirá declarando admisible o inadmisible el crédito o el privilegio. La resolución que lo declara admisible o inadmisible puede ser revisada a petición del interesado.

e) En Brasil, podrán formularse impugnaciones dirigidas en contra de la relación de acreedores publicada por el administrador, dentro de los diez días siguientes a dicha publicación. Luego, los acreedores cuyos créditos fueran impugnados serán intimados para oponerse a la impugnación, en el plazo de cinco días, adjuntando los documentos que tuvieren e indicando otras pruebas que consideren necesarias. El administrador judicial será intimado por el juez para expresar su opinión en el plazo de cinco días.

Cada impugnación será diligenciada por separado, junto con los documentos relativos a ella, pero se tramitarán juntas las impugnaciones que verse sobre el mismo crédito. Los autos serán entregados al juez para que dicte resolución, que:

- Determinará la inclusión en la nómina de acreedores de las habilitaciones de créditos no impugnados.

- Juzgará las impugnaciones que crea suficientemente esclarecidas por las alegaciones y pruebas presentadas por las partes, mencionando el valor y la clasificación de cada crédito.

- Fijará, en cada una de las impugnaciones, los aspectos controvertidos y resolverá las cuestiones procesales pendientes.

- Determinará las pruebas a ser producidas, designando audiencias de instrucción y juzgamiento si fuera necesario.

Ni la relación del administrador ni el informe pericial son vinculantes para el juez, que decidirá las impugnaciones cuando las crea suficientemente esclarecidas por los alegatos y pruebas, en todo caso en forma fundada, determinando su valor y graduación. La resolución judicial que decida sobre la impugnación podrá ser apelada.

La inexistencia de impugnaciones determina la homologación por el juez concursal de la nómina de acreedores, sin más trámite.

f) En Colombia, el "trámite del procedimiento de verificación es abreviado" 80 . Una vez que el promotor haya presentado el proyecto elaborado por el deudor al juez, se corre traslado por 10 días. Los acreedores podrán formular objeciones y proponer pruebas. De las objeciones se dará traslado por 5 días a todos los interesados quienes pueden a su vez proponer pruebas.

Vencido el término, se abrirá un breve interregno de 10 días, dentro del cual el promotor deberá provocar la conciliación de dichas objeciones, in-

${ }^{80}$ DAsso, Ariel Ángel, Derecho Concursal Comparado, Tomo I, $1^{\text {a }}$ ed., Legis, Buenos Aires, 2009, p. 417. 
formando en el plazo de dos días al juez del concurso sobre el resultado de la gestión.

Si no hubiera objeciones o el promotor las hubiere conciliado, el juez dictará la resolución de aprobación de inventario y verificación de créditos y establecerá los derechos de voto juntamente con la determinación del plazo para la presentación del acuerdo. Si, por el contrario, hubiere objeciones, el juez podrá disponer la producción de las pruebas. El período de producción no deberá exceder los 30 días y el juez decidirá en audiencia en que resolverá las cuestiones, aprobará el inventario, reconocerá los créditos y asignará los derechos de votos y plazo para la presentación del acuerdo.

g) En Estados Unidos ${ }^{81}$, la mayoría de los créditos se admitirán automáticamente. En efecto, los créditos se considerarán admitidos si se presenta la respectiva solicitud de verificación, a menos que el deudor, el síndico u otro acreedor, objeten. En caso de objeción, el tribunal, ordenará una notificación y fijará una audiencia, y luego determinará el monto del crédito.

h) En Finlandia, se sigue un procedimiento más complejo. Habiendo elaborado la primera versión de la "lista de desembolsos", dentro del plazo perentorio de un mes, cualquier acreedor, o el deudor, podrán controvertir el crédito de otro acreedor o su preferencia, fundada y detalladamente, lo cual deberán hacer por escrito ante el administrador. Un crédito o la preferencia de un crédito que no hayan sido controvertidos oportunamente o respecto del cual, habiendo sido controvertidos, el litigio haya sido desestimado, se considerarán aceptados.

En caso de controversia, el administrador otorgará al acreedor en cuestión la oportunidad de ser oído sobre el asunto y de presentar pruebas en apoyo de su crédito. Habiendo oído a los acreedores y al deudor, el administrador elaborará la lista de desembolsos, modificando la primera versión en la forma que considere apropiada, en atención a las controversias y declaraciones de las partes. Luego, presentará esta lista para certificación del tribunal, no mas allá de tres meses después del vencimiento del plazo para elaborar la primera versión de la lista. Si un crédito ha sido controvertido, el administrador adjuntará los documentos relativos a la controversia.

Una vez presentada la lista de desembolsos, el tribunal conocerá de las controversias y desacuerdos en relación con las presentaciones de los acreedores. Cualquier controversia infundada deberá ser rechazada. Si una controversia no puede ser resuelta sobre la base de la evidencia disponible, su conocimiento proseguirá de acuerdo con las disposiciones del procedimiento civil. El tribunal decidirá de esta forma los créditos controvertidos y, si procede, certificará la

${ }^{81}$ FerRiell, JefF y Janger, Edward J., Understanding Bankruptcy, Second Edition, LexisNexis, New York, 2007, pp. 337-339. 
lista de desembolsos y emitirá una resolución indicando qué créditos recibirán desembolsos. Esta decisión del tribunal será susceptible de apelación.

i) En Perú, dentro del plazo de cinco días posteriores a la publicación del aviso de la Secretaría, los acreedores o terceros apersonados al procedimiento podrán oponerse al reconocimiento del crédito de otro acreedor efectuado por la Secretaría, cuando consideren que median situaciones de fraude o irregularidades destinadas a conceder al titular beneficios crediticios que no le corresponden. Dichas oposiciones serán resueltas por la Comisión.

\section{Características destacadas de los procedimientos descritos}

a) Es frecuente que el proceso de verificación de créditos se inicie directamente ante el síndico o ante otra entidad administradora de la quiebra, pero no ante el juez como ocurre actualmente en Chile.

b) Sobre la forma de verificación de créditos, normalmente existen a disposición de los acreedores formularios bastante sencillos para tal efecto, los que a su vez indican la necesidad de adjuntar los documentos justificativos del crédito. Por otra parte, algunos países regulan la presentación electrónica de documentos.

c) Por lo general, una vez recibidas las solicitudes, el síndico elabora una lista teniendo por verificados determinados créditos, de acuerdo a los documentos presentados, y a la contabilidad y demás libros comerciales del deudor. Incluso, pueden tenerse por verificados créditos sin necesidad de que hayan sido reclamados por sus respectivos titulares, si constan no obstante en la información indicada ${ }^{82}$.

d) Luego, los acreedores, o bien tienen acceso a la información utilizada por el síndico, o bien tienen la posibilidad de asistir a una reunión en que se plantee y discuta sobre la verificación de créditos. Así, entran en conocimiento de la labor de verificación que ha efectuado el síndico y de los antecedentes que ha tenido a la vista para ello.

e) En base a lo anterior, los acreedores y el deudor pueden elegir impugnar o no un determinado crédito.

f) Esta impugnación, en algunos sistemas, se promueve ante el síndico, quien, junto con un informe que realiza sobre cada impugnación, la remite a su vez al juzgado. En otros sistemas, se interpone directamente ante tribu-

82 "Con esta previsión se pretende evitar que se malgasten recursos para participar en un procedimiento en el que ya son conocidos (por ejemplo, en términos de tiempo y de esfuerzo en acreditar su condición; de dinero invertido en pagar a un profesional que le asesore, etc.). Igualmente, se busca reducir los costes de administrar el sistema concursal minimizando la posibilidad de que se produzcan comunicaciones redundantes con la información ya existente" (Bermejo, "Comunicación", cit. nota n. 75, pp. 1529-1530). 
nales. Se aprecia cómo se persigue descargar de los hombros del juez toda labor que no sea propiamente jurisdiccional, a diferencia de lo que ocurre en el sistema chileno, en el tribunal está también a cargo de funciones más bien administrativas.

g) Normalmente se contempla la posibilidad de apelar en contra de la decisión sobre la impugnación.

\section{Propuesta a MOdo de CONClusión}

La pregunta que surge de lo expuesto en este trabajo, es la siguiente: ¿Se justifica la existencia de un sistema de verificación de créditos y de realización de activos, si su regulación no logra satisfacer exigencias mínimas de eficiencia? Resulta evidente que la respuesta a esta interrogante dependerá de si existen sistemas o regulaciones alternativas que sí conduzcan a satisfacer dichas exigencias.

En la sección anterior, se ha efectuado un análisis de Derecho comparado de distintos regímenes de verificación. Aquellos que conducen a resultados de mayor eficiencia -por ejemplo, Canadá8 ${ }^{83}$, Hong Kong ${ }^{84}$, Singapur ${ }^{85}-$, están estructurados sobre la base de una verificación propiamente administrativa, esto es, ante el órgano no judicial de gestión de la quiebra. En otras palabras, al tribunal de la quiebra no le corresponde la función de tramitar ni resolver las verificaciones y las objeciones que planteen a ellas los sujetos legitimados para hacerlo. Una vez resueltas las impugnaciones por el órgano de administración, la decisión de este último podrá ser reclamada por la parte agraviada ante el tribunal jurisdiccional competente. Adicionalmente, cabe destacar que la prosecución misma de la verificación está establecida sin excesivas formalidades. En

\footnotetext{
${ }^{83} \mathrm{Al}$ respecto, consultar: Office of the Superintendent of Bankruptcy Canada. Disponible en http:// www.ic.gc.ca/eic/site/bsf-osb.nsf/eng/home [visitado el 24/12/2011]. La normativa está contenida en los siguientes textos legislativos: Bankruptcy and Insolvency Act. Disponible en http://laws-lois.justice. gc.ca/eng/acts/B-3/index.html [consulta el 24 de diciembre de 2011]; Bankruptcy and Insolvence Rules. Disponible en http://laws-lois.justice.gc.ca/eng/regulations/C.R.C.,_C._368/index.html [consulta el 24 de diciembre de 2011]; Winding-up and Restructuring Act. Disponible en http://laws-lois.justice.gc.ca/ eng/acts/W-11/index.html [consulta el 24 de diciembre de 2011]; y, Companies' Creditors Arrangement Act. Disponible en http://laws-lois.justice.gc.ca/eng/acts/C-36/index.html [visitado el 24/12/2011].

${ }^{84} \mathrm{Al}$ respecto, consultar: Official Receiver's Office. Disponible en http://www.oro.gov.hk/eng/home/ home.htm [consulta el 24 de diciembre de 2011]. Existe una Ordenanza sobre Transacciones Electrónicas, que facilita la tramitación de la quiebra por Internet. Disponible en http://www.oro.gov.hk/eng/ electronic/submission.htm [visitado el 24/12/2011].

${ }^{85}$ Al respecto, consultar: Insolvency \& Public Trustee's Office. Disponible en http://app2.ipto.gov. sg/ [consulta el 24 de diciembre de 2011]. La regulación se encuentra contenida en las leyes sobre insolvencia de personas naturales e insolvencia de empresas. Disponible en http://statutes.agc.gov.sg/ [visitado el 24/12/2011].
} 
efecto, un crédito se puede verificar y objetar vía electrónica, implementándose al efecto un portal en Internet en que consta la tramitación respectiva, y a través del cual se puede notificar a las partes de las actuaciones y resoluciones que se dicten en el proceso. Con ello se reducen los costos de la notificación (comparándolo con el sistema de notificación por avisos de nuestra legislación sobre quiebras), y de tiempos jurisdiccionales pasivos (aquellos en que, por la inercia misma del procedimiento escrito, se generan horarios y días sin posibilidad de dar curso progresivo a los autos).

Por otro lado, la verificación administrativa permite asignar las funciones ínsitas y propias de la quiebra a los órganos mejor capacitados o preparados para resolver eventuales impugnaciones. En efecto, desde la dictación de la ley $N^{\circ} 20.004$, uno de los propósitos perseguidos por el legislador ha sido el de perfeccionar la función del síndico y, asimismo, dotarlo de mayor transparencia, sujetándolo en todo el campo de sus atribuciones a la vigilancia administrativa de la Superintendencia de Quiebras. Precisamente, esta mayor profesionalización debería conducir a asignar a dicho órgano de la quiebra, funciones técnicas para las cuales se encuentra mejor capacitado que el juez de la quiebra. Esto, a su vez, permitiría reducir los costos del error asociado a una decisión de verificación. Del mismo modo, reduciría los costos terciarios, ya que es de suponer que los tiempos de decisión son más expeditos cuando el órgano a quien compete la resolución respectiva tiene un mayor nivel de conocimiento sobre la materia que resuelve.

Por lo mismo, y en relación con el sistema de verificación de créditos, la propuesta que se contiene en este trabajo consiste en señalar que, de acuerdo al análisis económico del Derecho, la verificación de créditos debiera ser un trámite completamente administrativo. Esto implica que la presentación y tramitación de las solicitudes de verificación deba presentarse ante el síndico de la quiebra, quien administra el sistema, encargándose de sus notificaciones y decisiones. Asimismo, se deja a salvo la posibilidad de una reclamación en sede judicial. En atención a lo anterior, los lineamentos deberían ser los siguientes:

a) Establecimiento de un trámite de verificación administrativa a llevarse a cabo ante el síndico de la quiebras.

b) Los principios formativos aplicables debieran ser los de oficialidad, celeridad, publicidad, y una menor formalidad que la existente.

c) Existencia de un portal de Internet, cuya vía de acceso opere a través de la página web del poder judicial y de la Superintendencia de Quiebras. En dicho portal existiría un link de ingreso a cada quiebra, identificable por el síndico que la tiene a cargo.

d) Inclusión en dicho portal de un estado diario, de carácter administrativo, asociado a cada quiebra. 
e) La verificación podría efectuarse vía correo electrónico ${ }^{86}$ o por escrito. La verificación deberá cumplir en todo caso con los requisitos que al efecto exige el artículo 134 LQ.

f) Fijación de un plazo de verificación ordinaria de 30 días de duración, contados desde la fecha de notificación por avisos de la sentencia que declara la quiebra.

g) Este plazo tendría el carácter de fatal, y produciría consecuencias jurídicas en virtud de su sola expiración, siendo la más importante de ellas, el inicio de una etapa de verificación extraordinaria, a contar del día trigésimo primero siguiente a la notificación de la sentencia que declara la quiebra.

h) La verificación extraordinaria no debiera estar sujeta a plazo alguno, pudiendo presentarse la solicitud mientras existan bienes no realizados en procesos liquidatorios y repartos anteriores.

i) Una vez presentadas las verificaciones, éstas debieran ser publicadas en el estado diario mencionado precedentemente, contando el resto de los acreedores, el síndico y el fallido, con un plazo de 6 días para efectos de formular las observaciones e impugnaciones que estimen pertinentes de acuerdo a derecho.

j) Una vez vencido dicho plazo, se daría traslado de las observaciones e impugnaciones formuladas al acreedor verificante, por un plazo de 3 días.

k) El síndico resolvería las observaciones e impugnaciones en forma fundada, de plano o previa tramitación incidental. Los créditos reconocidos, en la medida que adquieran dicho carácter, ingresarían a una nómina que debiera mantenerse actualizada día a día en el portal web de internet ya aludido.

I) La tramitación incidental que el síndico pudiera disponer a fin de resolver las observaciones e impugnaciones que existan respecto de un crédito, se llevaría a cabo ante él mismo. Las partes tendrían la oportunidad hacer presente todos los medios de prueba necesarios a fin de fundar su posición. Cada parte dispondría de la posibilidad de acompañar informes periciales privados. La prueba testimonial debiera rendirse ante el juez de la quiebra, en presencia de

\footnotetext{
${ }^{86}$ La tramitación electrónica permite generar oportunidades de mayor acceso a la información, lo que aumenta los niveles de eficiencia, transparencia y publicidad. En este sentido, específicamente respecto del proceso de quiebras, el Banco Mundial ha señalado que: "Además de la información necesaria para que las empresas cumplan con las regulaciones, ciertas instituciones, como los tribunales, proporcionan información que contribuye a mejorar la transparencia en el mercado. Es necesario contar con tribunales eficientes y justos para generar la confianza que las empresas necesitan para construir nuevas relaciones y ampliar sus mercados, y para que los inversores inviertan. Pero no sólo su papel en el cumplimiento eficaz es importante. Doing Business ha detectado que, en caso el $75 \%$ de la muestra analizada de 151 economías, los tribunales deben por ley hacer pública la incoación de procedimientos de insolvencia" (Banco Mundial, Doing Business 2012: "Haciendo negocios en un mundo más transparente", 2010, p. 4).
} 
un receptor judicial. El hecho sustancial, pertinente y controvertido, consistiría en la efectividad de las observaciones e impugnaciones realizadas. La duración del periodo de prueba no debiera exceder de 8 días hábiles, luego de los cuales, existieren o no diligencias de prueba pendientes, el síndico se encontraría en situación de resolver, sin necesidad trámite alguno.

m) Se debería establecer que la decisión administrativa del síndico podrá ser reclamada ante el juez de la quiebra, aunque solamente en el caso que exista parte agraviada, entendiéndose por tal: (a) Aquella que realizó observaciones e impugnaciones que posteriormente no fueron acogidas, y (b) Aquel acreedor verificante cuyo crédito fue desestimado.

n) Este recurso de reclamación sería un medio recursivo de reforma, y debería ser presentado ante el síndico dentro del plazo de cinco días de notificada la decisión por el estado diario mencionado precedentemente.

o) El síndico debería remitir al juez de la quiebra copia íntegra y fidedigna de todo lo obrado en relación al crédito en cuestión, al día hábil siguiente de presentada la reclamación. El juez de la quiebra fallaría entonces dentro de décimo día de recibidos los antecedentes, y ante él solamente se podría rendir prueba documental. Contra de la decisión del juez de la quiebra no procedería recurso alguno, salvo el de queja.

p) El solo hecho de deducir un recurso de reclamación en contra de un crédito, imposibilitaría la intervención del acreedor respectivo en juntas de acreedores y su participación en repartos de fondos, a menos que el síndico disponga lo contrario.

Por otra parte, la propuesta acerca del sistema de realización de bienes pretende reducir los plazos de liquidación; optimizar las actividades del síndico en ciertas etapas del proceso de quiebras, haciéndolo más armónico; evitar litigación periférica en razón de situaciones de reembargo, y reducir ciertos plazos y formalidades del proceso de ejecución. En resumidas cuentas, se propone lo siguiente:

a) Reducir el plazo legal de realización del activo a cuatro meses para los bienes muebles, y a seis meses para los inmuebles, pudiendo ampliarse por una sola vez y por tres meses cada uno de dichos términos. Este plazo se cuenta desde que el síndico asuma oficialmente en su calidad de tal.

b) Establecer que el programa de realización del activo, el plan de pago del pasivo y la estimación de los gastos de la administración de la quiebra (artículo 111 LQ), sean presentados por el síndico en la primera junta de acreedores, y no en la primera junta ordinaria de acreedores.

c) Disponer que, en caso que el síndico provisorio no sea ratificado en su cargo, el nuevo síndico que se designe deberá presentar el programa, plan y estimación recién indicados, en un plazo no superior a 20 días. 
d) Agregar al artículo 1464 del Código Civil, un inciso final que establezca que tratándose de aquellos bienes inmuebles que deban realizarse en la quiebra, no se necesitará de autorización previa de otros tribunales que hayan ordenado embargo o medidas cautelares, bastando un oficio que al efecto dirija el juez de la quiebra a aquellos tribunales, una vez que el síndico le indique que el bien inmueble en cuestión forma parte de la masa activa.

e) Aplicar al proceso liquidatorio de quiebra, las reglas del Libro III, Título I, párrafo 2 del Código de Procedimiento Civil, titulado "De la administración de los bienes embargados y del procedimiento de apremio", con las siguientes modificaciones:

i. Los bienes inmuebles se venderán en pública subasta, a partir del valor de tasación que figure en el rol de avalúos.

ii.Reducir a dos los avisos señalados en el artículo 489 del Código de Procedimiento Civil.

iii. Eliminar la segunda parte del artículo 502 del Código de Procedimiento Civil.

iv. Disponer la publicación del remate en la página de la Superintendencia de Quiebra.

\section{BiBLIOGRAFÍA}

BANCo Mundial, Informe sobre Observancia de Estándares y Códigos, Chile, Junio 2004. Disponible en http://www-wds.worldbank.org/external/default/ main? menuPK=64187510\&pagePK=64193027\&piPK=64187937\&theSiteP $\mathrm{K}=523679 \&$ menuPK $=64154159 \&$ searchMenuPK $=64258544 \&$ theSitePK $=5$ 23679\&entitylD=000160016_20060126181835\&searchMenuPK=642585 44\&theSitePK=523679 [visitado el 20/03/2012].

Banco Mundial, Doing Business. Disponible en http://www.doingbusiness.org/ data/exploretopics/resolving-insolvency [visitado el 23/12/2011].

Baeza Ovalle, José Gonzalo, "Naturaleza jurídica del proceso concursal", Revista Chilena de Derecho, Vol. 38, № 1, 2011, pp. 35-56.

Bermejo, Nuria, "Comunicación de créditos" (Art. 85) en Rojo, Ángel y Beltrán, Emilio (dirs.), Comentario de la Ley Concursal, Thomson Civitas, Madrid, 2004.

BONILLA, Claudio; FisCher, Ronald; LüDers, Rolf; MerY, Rafael; y TAGLE, José, Análisis y Recomendaciones para una reforma de la ley de quiebras, Documentos de Trabajo del Centro de Economía Aplicada del Departamento de Ingeniería Industrial de la Universidad de Chile, 2004, № 191.

CAlabresi, Guido, El coste de los Accidentes: análisis económico y jurídico de la responsabilidad civil, t. Joaquín Bisbal, Editorial Ariel, Barcelona, 1984. 
Carrasco Delgado, Nicolás, "Hipoteca Legal en la legislación chilena de quiebras, a propósito de la enajenación como unidad económica", en Mauricio Tapia Rodríguez [et al.], Estudios sobre garantías reales y personales, Libro Homenaje al Profesor Manuel Somarriva Undurraga, Vol. I, Editorial Jurídica de Chile, Santiago, 2008.

Carrasco Delgado, Nicolás, Análisis económico del derecho de la tutela cautelar. Aplicación a la legislación civil y de quiebras en Chile, Tesis para optar al grado de Magíster en Derecho con mención en Derecho Económico, Escuela de Graduados Facultad de Derecho Universidad de Chile, 2011.

COASE, Ronald, "El problema del Costo Social", Revista de Estudios Públicos, No 45, 1992.

Contreras Strauch, Osvaldo, Insolvencia y Quiebra, Editorial Jurídica de Chile, Santiago, 2010.

COOTER, Robert y Ulen, Thomas, Derecho y EConomía, Fondo de Cultura Económica, México, DF, 1998.

Dasso, Ariel Ángel, Derecho Concursal Comparado, Tomos I y II, $1^{\text {a }}$ ed., Legis, Buenos Aires, 2009.

Ferriell, Jeff y Janger, Edward J, Understanding Bankruptcy, Second Edition, LexisNexis, New York, 2007.

Garaguso, Horacio y Medina, María Rosa, Verificación de Créditos en los Países del Mercosur, Ad-Hoc, Buenos Aires, 1998.

Goldenberg Serrano, Juan Luis, "Consideraciones críticas respecto al denominado principio de la par condictiocreditorum", Revista Chilena de Derecho, Vol. 37, No 1, 2010, pp. 73-98.

Gómez Balmaceda, Rafael, y Eyzaguirre Smart, Gonzalo, El derecho de quiebras, $2^{\mathrm{a}}$ ed. aum., Editorial Jurídica de Chile, Santiago, 2011.

Grisskopf, Ofer, y MeDina, Barak, Repairing (the Doctrine of) Irreparable Harm: Econmic Analysis of Preliminary Injunctions, 2008. Disponible en http:// works.bepress.com/barak_medina/6, [visitado el 20/12/2011].

Haugen, Robert, y Senbet, Lemma, Bankruptcy and Agency Costs: Their Significance to the Theory of Optimal Capital Structure, Journal of Financial and Quantitative Analysis, No 23, 1988, pp. 27-38.

Instructivo de la Superintendencia de Quiebras No 4, de fecha 29 de diciembre de 2009.

Instructivo $N^{\circ} 9$ de la Superintendencia de Quiebras, de fecha 29 de diciembre de 2009.

Karzulovic Dawson, Neva, Manual Práctico. Procedimiento sobre quiebras, Editorial Jurídica ConoSur, Santiago, 1985. 
LeUBSDORF, John, The Standard for Preliminary Injuctions, Harvard Law Review, 1978 ( No 91).

LiRa Silva, Diego, y Román Rodríguez, Juan Pablo, Reforma al Derecho de Quiebras. Nuevo Estatuto de los Síndicos, Editorial LexisNexis, Santiago, 2006.

Marinoni, Luiz Guilherme; Pérez Ragone, Álvaro y Núñez Ojeda, Raúl, Fundamentos del proceso civil. Hacia una teoría de la adjudicación, Abeledo Perrot/ Legalpublishing, Santiago, 2010.

Modigliani, Franco, y Miller, Merton, The Cost of Capital, Corporation Finance, and the Theory of Investment, American Economic Review, No 48, 1958, pp. 261-297.

Modigliani, Franco, y Miller, Merton, Corporate Income Taxes and the Cost of Capital, American Economic Review, No 53, 1963, pp. 433-443.

Núñez Ojeda, Raúl y Carrasco Delgado, Nicolás, Derecho concursal procesal chileno, AbeledoPerrot/Legalpublising, Santiago, 2011.

Nuñez Ojeda, Raúl, y Carrasco Delgado, Nicolás, "La quiebra sin bienes. Una aproximación desde el análisis económico del derecho", Revista lus et Praxis, año 17, No 1, 2011, pp. 139-176.

POSNer, Richard, El análisis económico del Derecho, Fondo de Cultura Económica, México, DF, 1992.

Puelma Accorsi, Álvaro, Curso de Derecho de Quiebras, 4ª ed. actualizada, Editorial Jurídica de Chile, Santiago, 1985.

Puga VIAL, Juan Esteban, Derecho Concursal. El Juicio de Quiebras, $3^{\text {a }}$ ed. actualizada, Editorial Jurídica de Chile, Santiago, 2004.

TORRes ZaGAL, Óscar, "Naturaleza jurídica de la resolución que resuelve sobre impugnación de crédito en el juicio de quiebra", Gaceta Jurídica, № 243, año 2000, pp. 11-13.

Sandoval López, Ricardo, Derecho comercial, Volumen 4, 6a ed. actualizada, Editorial Jurídica de Chile, Santiago, 2006.

SkARIC Carevic, Antonio, Reforma del sistema concursal chileno, sus fundamentos en el derecho internacional. Texto comparado de las Leyes $N^{\circ} 18.175$ y $N^{\circ} 4.558$, Memoria de prueba para optar al grado de Magíster en Derecho de la Contratación Comparada e Internacional, Facultad de Derecho Universidad de Chile, 1985.

UNCITRAL, Guía Legislativa sobre el Régimen de la Insolvencia, 2006. Disponible en http://www.uncitral.org/pdf/spanish/texts/insolven/05-80725_ Ebook.pdf [visitado el 24/03/2012]

VARAS LIRA, Felipe, "La enajenación como unidad económica en el derecho concursal chileno", en Juan Pablo Román Rodríguez (coord.), Salvamento de las empresas en crisis, Editorial Jurídica de Chile, Santiago, 2001. 
Veljanovski, Cento, Economía del Derecho, Trad. De La Maza, Íñigo y Mery, Rafael, Ediciones Diego Portales, Santiago, 2006

Wohlschlegel, Ansgar, The Economics of Corporate Bankruptcy Law, 2002. Disponible en http://archiv.ub.uni-heidelberg.de/volltextserver/ volltexte/2002/3087/pdf/DissVeroeff.pdf [visitado el 24/12/2011]. 